Article

\title{
Synthesis and Antimicrobial Activity of Metal-Containing Linseed Oil-Based Waterborne Urethane Oil Wood Coatings
}

\author{
Kun-Tsung Lu * and Jing-Ping Chang \\ Department of Forestry, National Chung Hsing University, 250, Kuo-Kuang Rd., Taichung 402, Taiwan; \\ guluwalala@gmail.com \\ * Correspondence: lukt@nchu.edu.tw; Tel.: +886-4-2284-0345 (ext. 122); Fax: +886-4-2287-3628
}

Received: 27 November 2019; Accepted: 13 March 2020; Published: 16 March 2020

\begin{abstract}
In this study, the antimicrobial agents of mono(hydroxyethoxyethyl)phthalate (M(HEEP) $\left.)_{2}\right)$ with different metal of $\mathrm{M}=\mathrm{Zn}, \mathrm{Mn}, \mathrm{Pb}$, and Ca were synthesized from diethylene glycol (DEG), phthalic anhydride (PA), and divalent metal acetates including calcium acetate, zinc acetate, manganese acetate, and lead acetate, respectively. The waterborne urethane oil (WUO) dispersions synthesized from linseed oil, diisocyanates (hexamethylene diisocyanate (HDI) and isophorone diisocyanate (IPDI)), dimethylolpropionic acid at $\mathrm{NCO} / \mathrm{OH}$ molars of 0.9 , by acetone processing method were described as in our previous report. The $\mathrm{M}(\mathrm{HEEP})_{2}$ antimicrobial agents as well as the commercial nanosilver powder were added into WUO dispersions as the antimicrobial coatings. The effects of various antimicrobial agents and dosages $(0.0,0.2,0.6,0.8,1.0,2.0$, and $4.0 \mathrm{phr})$ on antimicrobial activity of WUO films against gram-negative bacterium of Escherichia coli, gram-positive bacterium of Staphylococcus aureus, brown-rot fungus of Gloeophyllum trabeum, and white-rot fungus of Lenzites betulina were assessed. In addition, the film properties of the best antimicrobial WUO coatings were also examined. The results showed that the antimicrobial agents of mono(hydroxyethoxyethyl) phthalate $\mathrm{M}(\mathrm{HEEP})_{2}$ $(\mathrm{M}=\mathrm{Zn}, \mathrm{Mn}, \mathrm{Pb}$, and $\mathrm{Ca})$ powders should certainly be synthesized by FTIR, ${ }^{1} \mathrm{H}-\mathrm{NMR},{ }^{13} \mathrm{C}-\mathrm{NMR}$, and energy-dispersive $\mathrm{X}$-ray spectroscopy (EDS) identifications and the yields of them were $43-55 \%$. The results also revealed that the WUO film synthesizing with HDI films containing Zn(HEEP) of $2.0 \mathrm{phr}$ and $\mathrm{Pb}(\mathrm{HEEP})_{2}$ of $0.4 \mathrm{phr}$ had the best antibacterial activity for E. coli and S. aureus, respectively. The IPDI films containing $\mathrm{Zn}(\mathrm{HEEP})_{2}$ of $1.0 \mathrm{phr}$ had the best antibacterial activity for both E. coli and S. aureus. For antifungal activity, the WUO film synthesizing with HDI films containing $\mathrm{Pb}(\mathrm{HEEP})_{2}$ of $0.8 \mathrm{phr}$ and $\mathrm{Zn}(\mathrm{HEEP})_{2}$ of $2.0 \mathrm{phr}$ as well as IPDI films containing $\mathrm{Mn}(\mathrm{HEEP})_{2}$ of $0.2 \mathrm{phr}$ and $\mathrm{Zn}(\mathrm{HEEP})_{2}$ of $4.0 \mathrm{phr}$ had the best performances against G. trabeum and L. betulina, respectively. Comparing with commercial nanoAg powder, the $\mathrm{Zn}(\mathrm{HEEP})_{2}$ and $\mathrm{Pb}(\mathrm{HEEP})_{2}$ had a superior antifungal efficiency for G. trabeum and L. betulina, while it had a slightly inferior efficiency in the antibacterial activity for E. coli and S. aureus. On the properties of WUO films, adding metal-containing antimicrobial agents could slightly enhance the thermal stability, but lowered the gloss of all films, however, the $T_{\mathrm{g}}$ value increased for HDI film and decreased for IPDI film. In addition to this, they had no significant difference in the film properties including hardness, impact resistance, bending resistance, adhesion, mass retention, and light-fastness between the WUO films with and without adding antimicrobial agents.
\end{abstract}

Keywords: linseed oil; waterborne urethane oil; mono(hydroxyethoxyethyl) phthalate; antimicrobial activity; wood coatings 


\section{Introduction}

The dwindling petroleum supplies have enormously increased the material cost as well as deep environmental concerns. In order to reduce the reliance on petrochemicals, employing renewable resources, such as natural linseed oil, tung oil, or castor oil, to replace petroleum derivatives for manufacturing wood coatings [1-6] and currently, waterborne coatings have received more attention as a substitute for solvent-borne coatings due to their nontoxic and nonflammable character as well as the emission of lesser or no volatile organic compounds (VOCs) [7,8]. In addition, the safety, healthy, ecology, and amenity living environments are the goal for human life $[2,9,10]$. Consequently, introducing the antimicrobial function on the articles for daily use such as wood furniture and building materials will decrease significantly the pollution of bacteria and fungi. Zafar et al. [11] reported that zinc incorporated linseed oil based polyesteramide was successfully synthesized at a lower temperature without an organic solvent. It was found that minor incorporation of zinc in linseed oil based polyesteramide exhibited improved antibacterial activities against Escherichia coli and Staphylococcus aureus. Zafar et al. [12] also founded that zinc and cadmium incorporated linseed oil based poly(esteramide-urethane) (Zn/Cd-LPEAUr) were performed against E. coli and S. aureus, and compared with those of petroleum-based metal containing polyurethanes. Zafar et al. $[13,14]$ further reported that Zn-containing self-cured Pongamia glabra oil based polyesteramide (Zn-APGPEA) resin and linseed oil based metallopolyesteramides (Mn(II)-/Co(II)-/Cu(II)-LPEA) containing metals resins can be used as an excellent antibacterial performance material against E. coli and S. aureus. Hsu et al. [15] prepared nanocomposites from a polyester-type waterborne polyurethane (PU) containing various low concentrations of silver nanoparticles (nanoAg) and found that nanoAg could not only improve the physical properties and biocompatibility of $\mathrm{PU}$, but also inhibit the growth of bacteria of Bacillus subtilis and E. coli. Li et al. [16] found that PU films doped with $\mathrm{ZnO}$ nanoparticles showed excellent antibacterial activity, especially for E. coli. Jayakumar et al. [17-19] prepared the metal salts of mono(hydroxyethoxyethyl)phthalate by reacting phthalic anhydride with diethylene glycol and metal acetate, where metal is $\mathrm{Cu}^{2+}, \mathrm{Mn}^{2+}$, and $\mathrm{Zn}^{2+}$. The metal-containing polyurethanes in the main chain were further synthesized by reacting hexamethylene diisocyanate (HMDI) or toluene 2,4-diisocyanate (TDI) with the salts of mono(hydroxyethoxyethyl)phthalate. It also found that these metal-containing polyurethanes had antibacterial activity against E. coli, Pseudomonas fluorescence, Streptococcus sp., and Salmonella sp. From the reports mentioned above, exhibiting the metal-containing materials possess the antimicrobial activity. However, in our pre-experiments on the mono(hydroxyethoxyethyl)phthalate reacting with diisocyanates, the polyurethanes materials would be gelled. The results were also confirmed by Matsuda [20], who reported that the polyurethane obtained were glassy materials or white powders. It is difficult to carry out in practical wood finishing. Therefore, in this study the mono(hydroxyethoxyethyl) phthalate were synthesized alone and the powders were used as additives or fillers for antimicrobial agents.

In this study, the waterborne urethane oil (WUO) dispersions synthesized from linseed oil, diisocyanates (hexamethylene diisocyanate and isophorone diisocyanate), dimethylolpropionic acid at various $\mathrm{NCO} / \mathrm{OH}$ molars of $0.7,0.8$, and 0.9 , are described as in our previous report [21]. In addition, the films properties of the WUOs for wood coatings are listed in another report [22]. The results showed that all of the WUO films had excellent adhesion, durability, and lightfastness, especially the HDI-0.9 (hexamethylene diisocyanate and NCO/OH molars of 0.9) and IPDI-0.9 (isophorone diisocyanate and $\mathrm{NCO} / \mathrm{OH}$ molars of 0.9 ) have balance properties between the coating and film of WUO, and are suitable for an oil finishing wood coating. Therefore, the linseed oil-based waterborne urethane oil wood coatings, HDI-0.9 and IPDI-0.9, were used in this study. Furthermore, the antimicrobial agents of mono(hydroxyethoxyethyl)phthalate $\left(\mathrm{M}(\mathrm{HEEP})_{2}\right)$ with a different metal of $\mathrm{M}=\mathrm{Zn}, \mathrm{Mn}, \mathrm{Pb}$, and $\mathrm{Ca}$ were also synthesized. The different types and various dosages of antimicrobial agents as well as the commercial nanoAg powder, which is known to have antimicrobial properties [15] as a control group were added into WUOs as antimicrobial wood coatings for a finishing on furniture and building materials. The antimicrobial activity of WUO films against Gram-negative 
bacterium of Escherichia coli, Gram-positive bacterium of Staphylococcus aureus, brown-rot fungus of Gloeophyllum trabeum, and white-rot fungus of Lenzites betulina were assessed. In addition, the film properties of the best antimicrobial wood coatings were also examined.

\section{Materials and Methods}

\subsection{Materials}

Diethylene glycol (DEG), divalent metal salts including calcium acetate, zinc acetate, manganese acetate, and lead acetate, which are hydrated, were purchased from Choneye Pure Chemicals Co. Ltd. (Taichung, Taiwan). Phthalic anhydride (PA) was purchased from Shimakyu's Pure Chemicals Co. Ltd. (Osaka, Japan). Commercial nanosilver powder (nanoAg), which is a composite with zirconium phosphate and the nanosilver content was $6 \%$ and was purchased from Chin-Tai Resins Chemical Co. Ltd. (Taichung, Taiwan). Methanol was purchased from Aencore Chemical Co. (Surrey Hills, Australia). Acetone was purchased from Union Chemical Works Ltd. (Taichung, Taiwan). Deionized water was prepared in our laboratory. A waterborne metal dryer including cobalt (Co-dryer, metal content of $5 \mathrm{wt} \%$ ), zirconium (Zr-dryer, metal content of $12 \mathrm{wt} \%$ ), and calcium (Ca-dryer, metal content of $5 \mathrm{wt} \%$ ) dryers were supplied by Qing Yi Co. Ltd. (Taichung, Taiwan). A filter paper disc was obtained from Toyo Roshi Kaisha, Ltd. (Bunkyo-ku, Japan). Culture media of potato dextrose agar (PDA) was purchased from Merck Taiwan Ltd. (Taipei, Taiwan). Microbial strains including Escherichia coli (Gram-negative bacterium), Staphylococcus aureus (Gram-positive bacterium), Gloeophyllum trabeum (brown-rot fungus), and Lenzites betulina (white-rot fungus) were purchased from the Food Industry Research and Development Institute (Hsinchu, Taiwan). Cryptomeria japonica boards (with a moisture content of $10.7 \%$ ), glass sheets, tin-coated iron sheets, and Teflon sheets were all prepared as specified by the CNS 9007 Standard [23] and were used as experimental substrates for film properties testing.

\subsection{Preparation of Waterborne Urethane Oil (WUO)}

The waterborne urethane oil (WUO) dispersions synthesized from linseed oil, diisocyanates (hexamethylene diisocyanate (HDI) and isophorone diisocyanate (IPDI)), and dimethylolpropionic acid at $\mathrm{NCO} / \mathrm{OH}$ molars of 0.9 by the acetone processing method were described as in our previous report [21]. The linseed oil glyceride (LOG) was first synthesized by using a transesterification process with a glycerol/linseed oil molar ratio of 1.0. Then the dimethylolpropionic acid reacted with HDI or IPDI, followed by adding LOG at NCO/OH molars of 0.9 , and the $\mathrm{COOH}$-containing prepolymer was obtained. Then, the ionomer, which was prepared by a neutralizing prepolymer with trimethylamine, was dispersed by adding deionized water, and the water-acetone dispersion was obtained. Finally, the acetone was removed by vacuum distillation and the WUO were obtained, respectively, and named the HDI- 0.9 coating and IPDI- 0.9 coating.

\subsection{Synthesis and Identification of Metal Containing Mono(hydroxyethoxyethyl) Phthalate $\left(M(H E E P)_{2}\right)$}

The synthesis method referred Jayakurmar et al. [17] and Matsuda [20] reports and we modified the process as follows. The 4 mole diethylene glycol (DEG) and 1 mole phthalic anhydride (PA) were placed in a four-neck reaction flask. The mixture was stirred and temperature rose up to $135^{\circ} \mathrm{C}$ and maintained for $1.5 \mathrm{~h}$. Then 0.5 mole divalent metal acetates (metal $(\mathrm{M})=\mathrm{Ca}, \mathrm{Zn}$, $\mathrm{Mn}$, and $\mathrm{Pb}$ ) were added respectively and the reaction temperature of the mixtures was adjusted to a specific temperature, i.e., $162{ }^{\circ} \mathrm{C}$ for calcium acetate, $150{ }^{\circ} \mathrm{C}$ for zinc acetate, $140{ }^{\circ} \mathrm{C}$ for manganese acetate, and $135{ }^{\circ} \mathrm{C}$ for lead acetate. When the specific temperature reached, the mixture was continued stirred at the temperature for another $3 \mathrm{~h}$. During the synthesis process, the appearance of the mixture transferred to milk white color and insoluble precipitates produced. Subsequently, the reaction system was cooled to room temperature and using acetone, methanol, and xylene washed the insoluble precipitates repeatedly. The powder of the metal containing mono(hydroxyethoxyethyl) phthalate (M(HEEP)2) was obtained and oven dried at $60^{\circ} \mathrm{C}$ for 3 days. The structure, appearance, 
and constituents of the powders were identified by Fourier-transform infrared spectroscopy (FTIR; Perkin-Elmer Spectrum 100 spectrometer using ATR mode; PerkinElmer, Waltham, MA, USA), nuclear magnetic resonance (NMR; Aglient Technologies DD2-600Hz, including 1H-NMR and 13C-NMR; Agilent Technologies, CA, USA), field emission scanning electron microscopes (FE-SEM; JEOL JSM-6700F; Japan Electron Optics Laboratory Co., Ltd., Tokyo, Japan), and energy-dispersive X-ray spectroscopy (EDS; Oxford X-Act $10 \mathrm{~mm} 2$, Oxford Instruments, Abingdon, Oxfordshire, England), respectively.

\subsection{Determination of Antimicrobial Activity}

Antibacterial and antifungal activities of $\mathrm{M}(\mathrm{HEEP})_{2}$-containing WUO coatings were investigated by the agar disk diffusion method [24,25]. A $39 \mathrm{~g} / \mathrm{L}$ of potato dextrose agar (PDA) sterilized in an autoclave sterilizer as a culture medium. The $0.1 \mathrm{~mL}$ of prepared culture suspension (ca. $10^{7}-10^{8}$ $\mathrm{cfu} / \mathrm{mL})$ was spread on the solidification surfaces of the agar culture medium $(20 \mathrm{~mL})$ on a petri dish. The dosages of various $\mathrm{M}(\mathrm{HEEP})_{2}, \mathrm{M}=\mathrm{Ca}, \mathrm{Zn}, \mathrm{Mn}$, and $\mathrm{Pb}$ and commercial nanoAg powders were 0.2 , $0.4,0.6,0.8,1.0,2.0$, and $4.0 \mathrm{phr}$ according to the solid content of the WUO coating and the mixtures were shaken by ultrasonic waves for $1 \mathrm{~h}$. Then the filter paper disks ( $8 \mathrm{~mm}$ in diameter) were first impregnated with WUO coatings for $5 \mathrm{~min}$, followed by being air dried for 3 days and then sterilized by UV radiation for $8 \mathrm{~h}$. The sterile filter paper disks were put on agar surfaces. The zones of growth inhibition around the disks were measured after $16-24 \mathrm{~h}$ of incubation at $37^{\circ} \mathrm{C}$ for bacteria and 3 days for fungi at $25^{\circ} \mathrm{C}$. According to the sizes of the inhibitory zone (including the diameter of disk) on the agar surface around the disks, the antimicrobial activity was graded as: - inactive $(0-9 \mathrm{~mm})$; + mildly active $(10-15 \mathrm{~mm}) ;++$ moderately active $(16-20 \mathrm{~mm})$; and +++ highly active $(\geq 21 \mathrm{~mm})$, respectively $[18,19]$. An average value and standard deviation of triplicate measurements was reported.

\subsection{Determination of the Film Properties of WUO Coatings}

The best antimicrobial activity of $\mathrm{M}(\mathrm{HEEP})_{2}$-containing the WUO coating was chosen to determine the film properties and the commercial nanoAg-containing one was used as a control group. The $0.3 \mathrm{wt} \%$ of the waterborne metal dryer including cobalt, zirconium, and calcium dryers were added to the WUO coating respectively, by the weight of the solid content of the coating and stirred for $30 \mathrm{~min}$. The selected substrates were coated using a universal applicator with a wet film thickness of $250 \mu \mathrm{m}$, and were placed in a constant temperature for $10 \mathrm{~min}$ and then on the oven at $50^{\circ} \mathrm{C}$ for another $10 \mathrm{~min}$, followed by drying in an air-conditioned environment at $26^{\circ} \mathrm{C}$ and $60 \% \mathrm{RH}$ for 30 days. The tests were carried out after this drying process.

The hardness of tested film on glass sheets was conducted using a König/Persoz Pendulum Hardness Tester (Braive Instruments, Liège, Belgium), according to the ISO 1522 [26]. Ten points were tested with the values averaged for each specimen. Impact resistance of films on wood was investigated based on the falling weight was $300 \mathrm{~g}$ and an impact needle diameter of $2.54 \mathrm{~cm}$ by using the Dupont Impact Tester IM-601 The bending resistance of tested films on tin-coated iron sheets was carried out according to JIS-K-5400 [27] by using a bending tester (Ueshima Seisakusho Co., Ltd., Tokyo, Japan) with steel bars diameters of 2,3,4,6,8, and $10 \mathrm{~mm}$. The adhesion of tested films on wood was performed by using the crosscut method according to CNS 10756 K 6800 [28]. The best adhesion is Grade 10 followed by Grades 8, 6, 4, 2, and 0 . The mass retention of tested films, which were first coated on Teflon sheets and then were separated off as a free film, was determined by putting each given weighted films into a Soxhelt extractor (Dogger Co., New Taipei City, Taiwan) containing $250 \mathrm{~mL}$ acetone. The solution was siphoned four times per hour (total $6 \mathrm{~h}$ ), and the soaked film was dried in an oven at $50{ }^{\circ} \mathrm{C}$ for $6 \mathrm{~h}$ and the weight retention was calculated. The gloss of films coated on wood panels and parallel to wood grain was detected by using a Dr. Lange $60^{\circ}$ Reflectometer (Dr. Bruno Lange $\mathrm{GmbH}$, Berlin, Germany). The tests mentioned above were performed at least triplicate and averages were recorded. 
The lightfastness of films coated on white card paper was carried out with a Paint Coating Fade Meter (Suga Test Instruments, Japan). The light source was mercury light (H400-F), and chamber temperature was $32 \pm 4{ }^{\circ} \mathrm{C}$. After a given exposure time, the changes in color of the specimens were measured with a spectrophotometer (CM-3600d, Minolta. Osaka, Japan) with an 8 mm target mask and fitted with a D65 light source with a measuring angle of $10^{\circ}$. The tristimulus values $\mathrm{X}, \mathrm{Y}$, and $\mathrm{Z}$ of all specimens were obtained directly from the colorimeter. The CIE $\mathrm{L}^{*}, \mathrm{a}^{*}$, and $\mathrm{b}^{*}$ color parameters were then computed, followed by calculating the color difference $\left(\Delta \mathrm{E}^{*}\right)$. Dynamic mechanical analysis (DMA) of the films, which were prepared the same as the mass retention tested film, was to determine the glass transition temperature $\left(T_{\mathrm{g}}\right)$ based on a single mode using a PerkinElmer DMA 8000 (PerkinElmer, Waltham, MA, USA). The test was performed in a nitrogen atmosphere and the resonance frequency was adjusted to $1 \mathrm{~Hz}$. with the temperature increasing from -50 to $150{ }^{\circ} \mathrm{C}$ at a heating rate of $2{ }^{\circ} \mathrm{C} \mathrm{min}-1$. The thermogravimetric analysis (TGA) of the films, which were prepared the same as mass retention tested film, was conducted using a PerkinElmer STA 6000 (PerkinElmer, Waltham, MA, USA) in a nitrogen atmosphere with the temperature increasing from 50 to $700{ }^{\circ} \mathrm{C}$ at a heating rate of $10{ }^{\circ} \mathrm{C} \min ^{-1}$.

\section{Results and Discussion}

\subsection{Synthesis and Identification of Metal Containing Mono(hydroxyethoxyethyl) Phthalate $\left(M(H E E P)_{2}\right)$}

In our pre-experiment, the metal containing mono(hydroxyethoxyethyl) phthalate $\left(\mathrm{M}(\mathrm{HEEP})_{2}\right)$ was synthesized from diethyl glycol (DEG), phthalate (PA), and various of metal acetates including Zn, $\mathrm{Mn}, \mathrm{Pb}$, and $\mathrm{Ca}$ acetates at $60-70{ }^{\circ} \mathrm{C}$ as described in Matsuda [20] and Jayakurmar et al. [17], however, the yields of $\mathrm{M}(\mathrm{HEEP})_{2}$ were only $4-5 \%$. In our modified process, the mixture of PA and DEG was stirred and temperature was rose up to $135^{\circ} \mathrm{C}$, which was higher than the melt point of PA of $131^{\circ} \mathrm{C}$, and maintained for $1.5 \mathrm{~h}$ to obtain mono diglycolic phthalate. Then the divalent metal acetates were added respectively, and the reaction temperature of the mixtures was adjusted to a specific temperature (as listed in Table 1) according to the insoluble precipitates produced. When the specific temperature reached, the mixture was continued stirred at the temperature for another $3 \mathrm{~h}$. The results showed that the yields of the $\mathrm{M}(\mathrm{HEEP})_{2}$ were increased to $43.4-55.1 \%$. The appearance of the $\mathrm{M}(\mathrm{HEEP})_{2}$ powder was a milk white color except the $\mathrm{Mn}(\mathrm{HEEP})_{2}$ powder was a light pink color as shown in Figure 1.

Table 1. Synthesis temperature, yield, and color of various $\mathrm{M}(\mathrm{HEEP})_{2}(\mathrm{M}=\mathrm{Zn}, \mathrm{Mn}, \mathrm{Pb}$, and Ca).

\begin{tabular}{cccc}
\hline $\mathbf{M}(\text { HEEP })_{2}$ & Synthesis Temperature $\left({ }^{\circ} \mathbf{C}\right)$ & Yield $(\%)$ & Color \\
\hline $\mathrm{Zn}(\mathrm{HEEP})_{2}$ & 150 & 55.1 & Milk white \\
$\mathrm{Mn}(\mathrm{HEEP})_{2}$ & 140 & 54.0 & Light pink \\
$\mathrm{Pb}(\mathrm{HEEP})_{2}$ & 135 & 51.8 & Milk white \\
$\mathrm{Ca}(\mathrm{HEEP})_{2}$ & 162 & 43.4 & Milk white \\
\hline
\end{tabular}
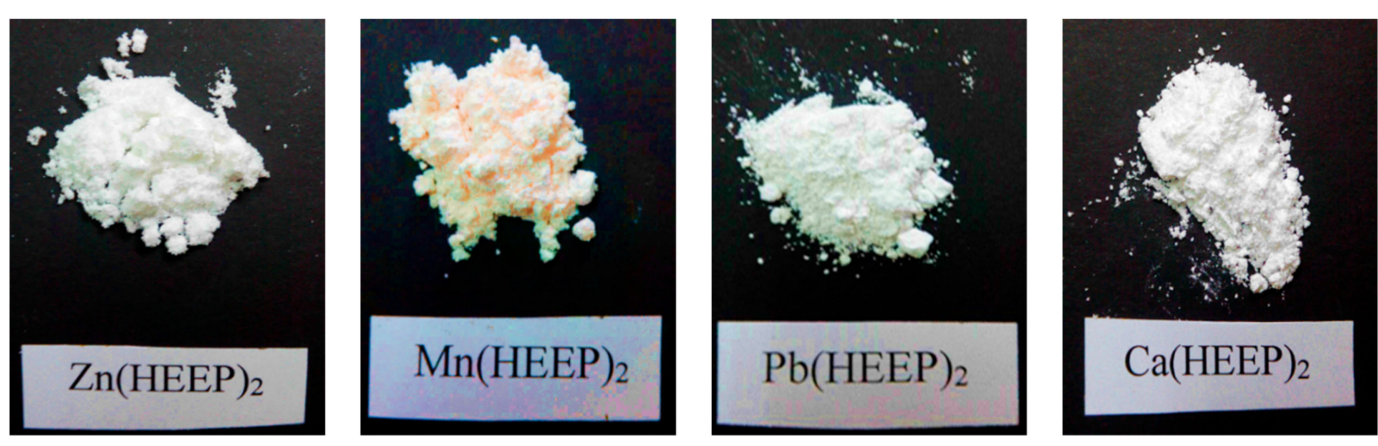

Figure 1. Appearance of $\mathrm{M}(\mathrm{HEEP})_{2}(\mathrm{M}=\mathrm{Zn}, \mathrm{Mn}, \mathrm{Pb}$, and $\mathrm{Ca})$. 
The FTIR spectra of $\mathrm{M}(\mathrm{HEEP})_{2}$ are shown in Figure 2. A broad absorption peak at $3400-3500 \mathrm{~cm}^{-1}$, which indicates the presence of $\mathrm{OH}$ groups and the peak that represents the carbonyl $(\mathrm{C}=\mathrm{O})$ group stretching vibration was observed at $1700-1730 \mathrm{~cm}^{-1}$. The peaks at $1400-1430$ and $1545-1570 \mathrm{~cm}^{-1}$ indicate the ion bonding vibrations between carbonyl group and metal ions. In addition, peaks at $1080-1130 \mathrm{~cm}^{-1}(\mathrm{C}-\mathrm{O}-\mathrm{C}$ stretching vibration), $1045-1060 \mathrm{~cm}^{-1}$ (primary alcohol of C-O stretching vibration), and $725-735 \mathrm{~cm}^{-1}$ (C-H out of plane bending vibration of the benzene ring) $[11,13,17-20]$ indicates that $\mathrm{M}(\mathrm{HEEP})_{2}$ was readily synthesized.

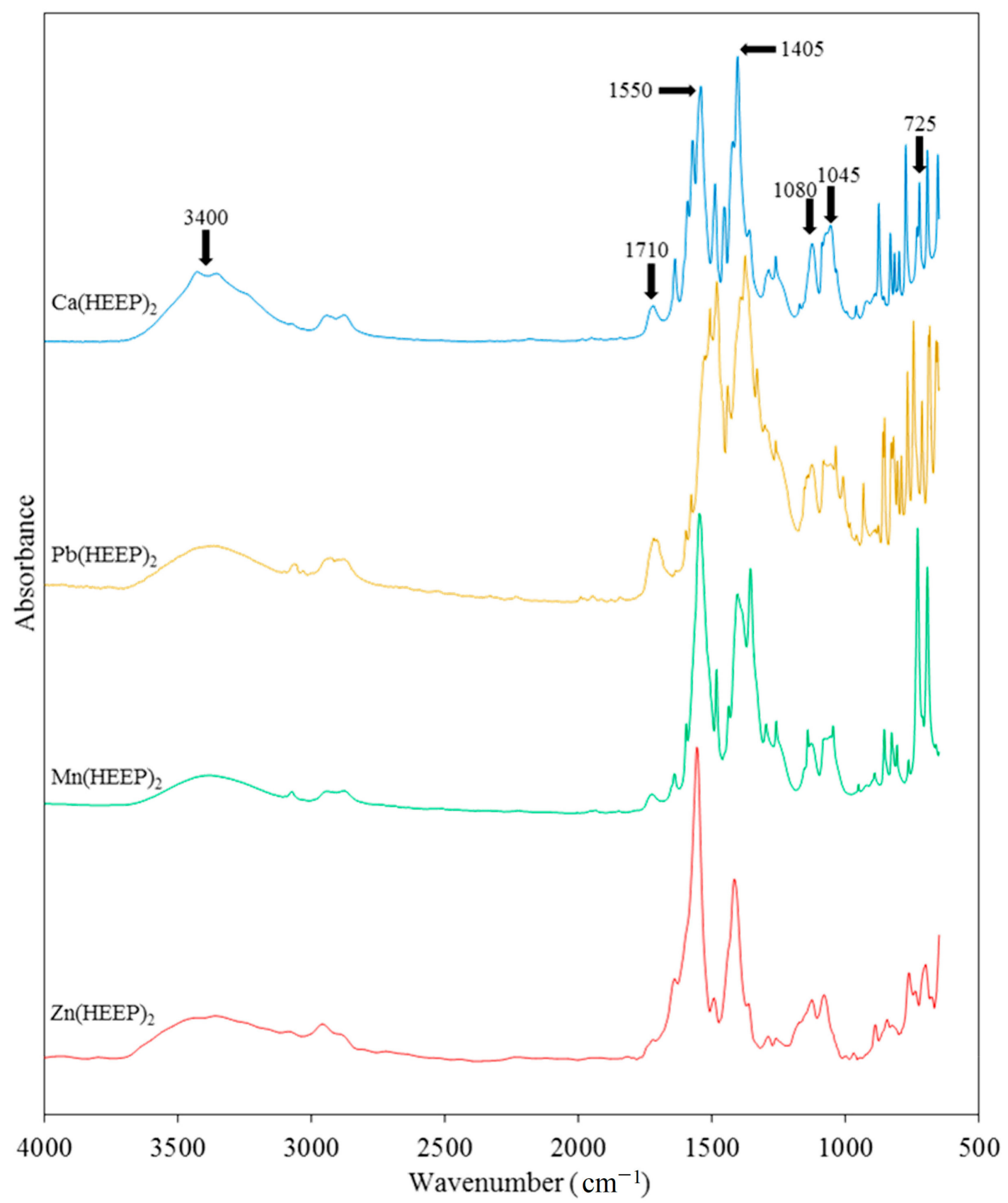

Figure 2. FTIR spectra of $\mathrm{M}(\mathrm{HEEP})_{2}(\mathrm{M}=\mathrm{Zn}, \mathrm{Mn}, \mathrm{Pb}$, and $\mathrm{Ca})$.

The structures of $\mathrm{M}(\mathrm{HEEP})_{2}$ were also investigated by NMR spectrometry. Taking Ca(HEEP $)_{2}$ as an example, the ${ }^{1} \mathrm{H}-\mathrm{NMR}$ and ${ }^{13} \mathrm{C}$-NMR spectra are displayed by Figures 3 and 4 , respectively. In the ${ }^{1} \mathrm{H}-\mathrm{NMR}$ spectrum, the signals were observed in the 7.41-7.48 ppm (H1), which corresponded to the aromatic proton. The signals with the chemical shift at $4.21-4.25 \mathrm{ppm}(\mathrm{H} 2)$ could be assigned to the proton of $-\mathrm{COOCH}_{2-}$, and the proton of $-\mathrm{OH}$ shows signals at 3.86-3.88 ppm. (H3) The peaks 
at the 3.71-3.76 ppm (H4) region could be attributed to the methylene group proton of $\mathrm{R}-\mathrm{COOAr}$, and the protons of $-\mathrm{CH}_{2}-\mathrm{O}-\mathrm{CH}_{2}$ - show signals at 3.61-3.64 ppm (H5) $[11,13,17-20]$.

The ${ }^{13} \mathrm{C}-\mathrm{NMR}$ spectrum of $\mathrm{Ca}(\mathrm{HEEP})_{2}$ (Figure 4 ) shows the carbon of $\mathrm{COO}$ - bonding with $\mathrm{Ca}$ (C12) and COO- adjacent to $\mathrm{CH}_{2}$ (C5) at 176.7-177.1 ppm and $169.3 \mathrm{ppm}$, respectively. The signal at $136.2 \mathrm{ppm}$ (C11) and $132.5 \mathrm{ppm}$ (C6) assigned to the carbon atoms of the aromatic group attached to COO-. The aromatic carbons $\mathrm{C} 7, \mathrm{C} 8, \mathrm{C} 9$, and $\mathrm{C} 10$ appeared in the $126.6-129.3 \mathrm{ppm}$ regions. The carbon of the methylene shows a peak at $71.5 \mathrm{ppm}(\mathrm{C} 1)$ for $-\mathrm{CH}_{2}-\mathrm{OH}$, at $71.7 \mathrm{ppm}(\mathrm{C} 4)$ for $-\mathrm{CH}_{2} \mathrm{OOC}-\mathrm{Ar}$, at $60.3 \mathrm{ppm}(\mathrm{C} 2)$ for $-\mathrm{CH}_{2}-\mathrm{CH}_{2} \mathrm{OH}$, and $68.2 \mathrm{ppm}$ (C3) for $-\mathrm{CH}_{2}-\mathrm{CH}_{2} \mathrm{OOC}-\mathrm{Ar}[11,13,17-20]$. These results indicated clearly that the $\mathrm{Ca}(\mathrm{HEEP})_{2}$ was synthesized successfully from DEG, PA, and calcium acetate.

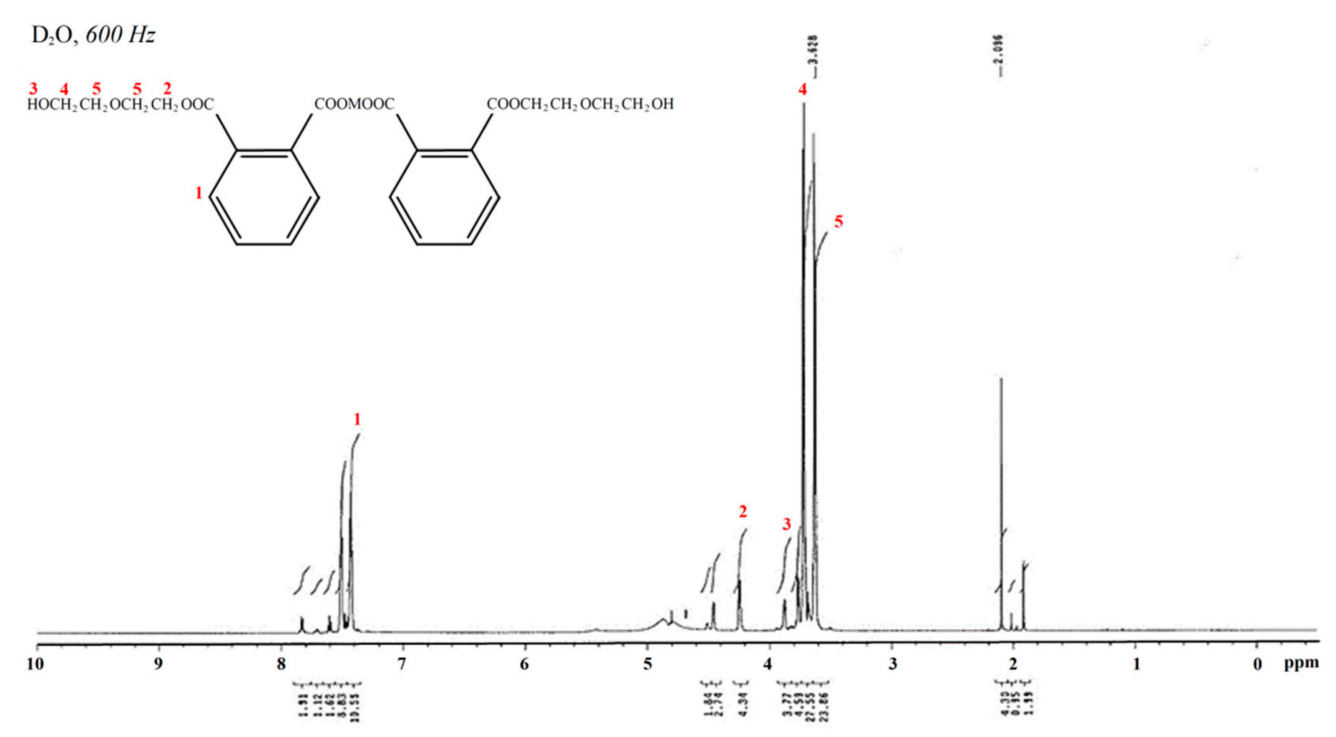

Figure 3. ${ }^{1} \mathrm{H}-\mathrm{NMR}$ spectrum of $\mathrm{Ca}(\mathrm{HEEP})_{2}$.

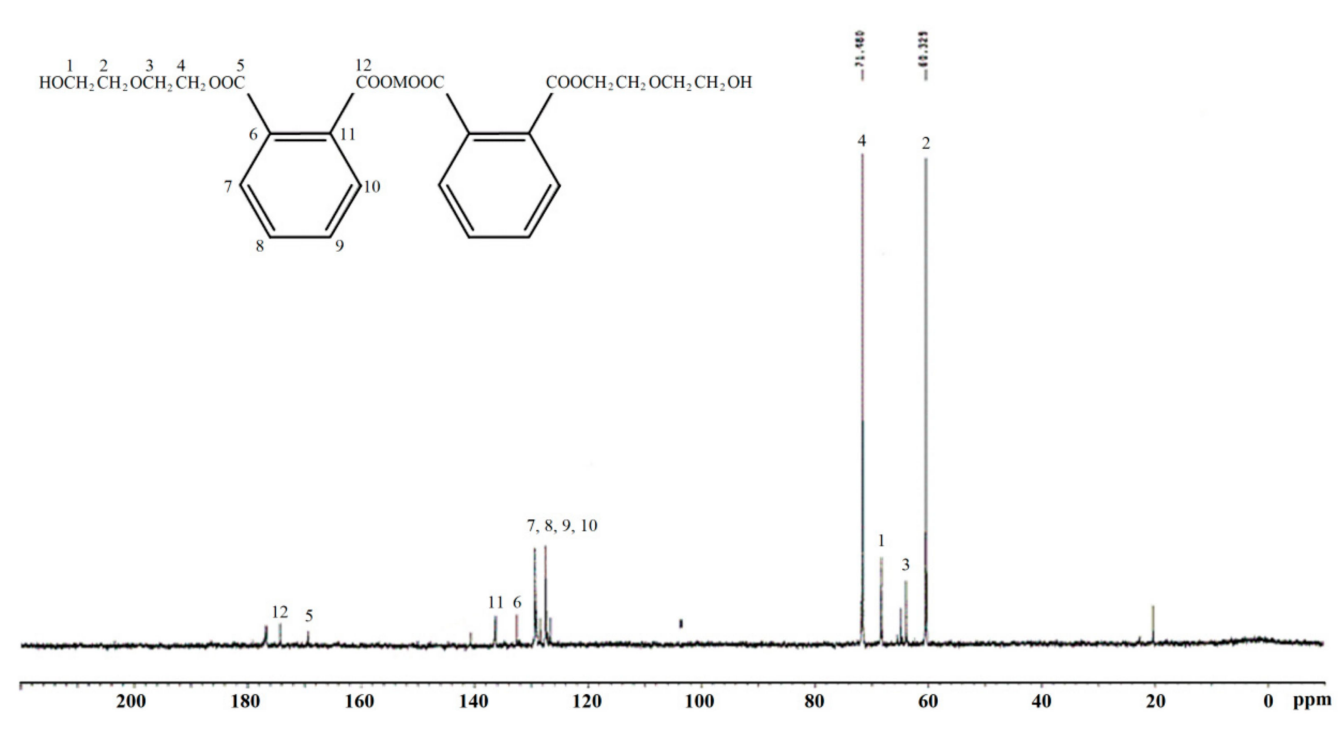

Figure $4 .{ }^{13} \mathrm{C}-\mathrm{NMR}$ spectrum of $\mathrm{Ca}(\mathrm{HEEP})_{2}$.

The morphologic characterization of $\mathrm{M}(\mathrm{HEEP})_{2}$ was determined by the FE-SEM analysis as listed in Figure 5. The $\mathrm{Zn}(\mathrm{HEEP})_{2}$ was piled as a sheet-like shape and had the largest size; the Ca(HEEP) ${ }_{2}$ was piled as a columnar shape; the $\mathrm{Mn}(\mathrm{HEEP})_{2}$ was piled as a spherical shape; and the $\mathrm{Pb}(\mathrm{HEEP})_{2}$ was piled as a lumpy shape and had the smallest size. The different morphology and size of M(HEEP $)_{2}$ crystals may be due to the different nucleation during the synthesis process [29]. The melt points of zinc acetate $\left(200^{\circ} \mathrm{C}\right)$ and calcium acetate $\left(160^{\circ} \mathrm{C}\right)$ were higher than or equal to the synthesis 
temperature (as shown in Table 1), resulting in an uneven nucleation and obtaining a larger size crystal. On the contrary, the manganese acetate and lead acetate had a lower melt point of 80 and $75{ }^{\circ} \mathrm{C}$, which was also lower than the synthesis temperature, attributing to an even nucleation and a smaller size crystal obtained. In addition, the EDS was used for confirming the metal ions were introduced into the mono(hydroxyethoxyethyl) phthalate as displayed by Figure 6. The results further revealed that the $\mathrm{M}(\mathrm{HEEP})_{2}(\mathrm{M}=\mathrm{Zn}, \mathrm{Mn}, \mathrm{Pb}$, and $\mathrm{Ca})$ were synthesized successfully as shown in Scheme 1.
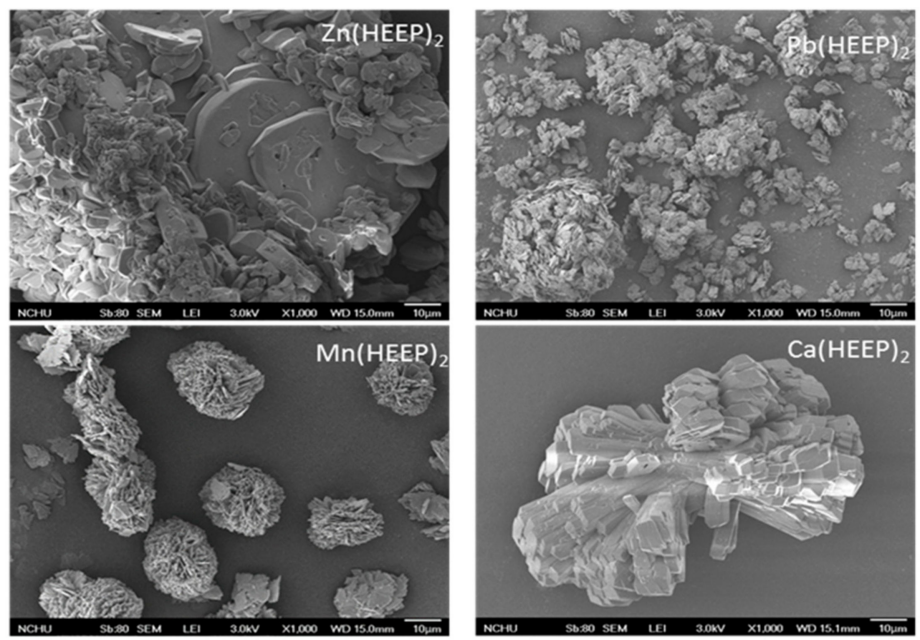

Figure 5. FE-SEM images (1000 $\times)$ of $\mathrm{M}(\mathrm{HEEP})_{2}(\mathrm{M}=\mathrm{Zn}, \mathrm{Mn}, \mathrm{Pb}$, and $\mathrm{Ca})$.
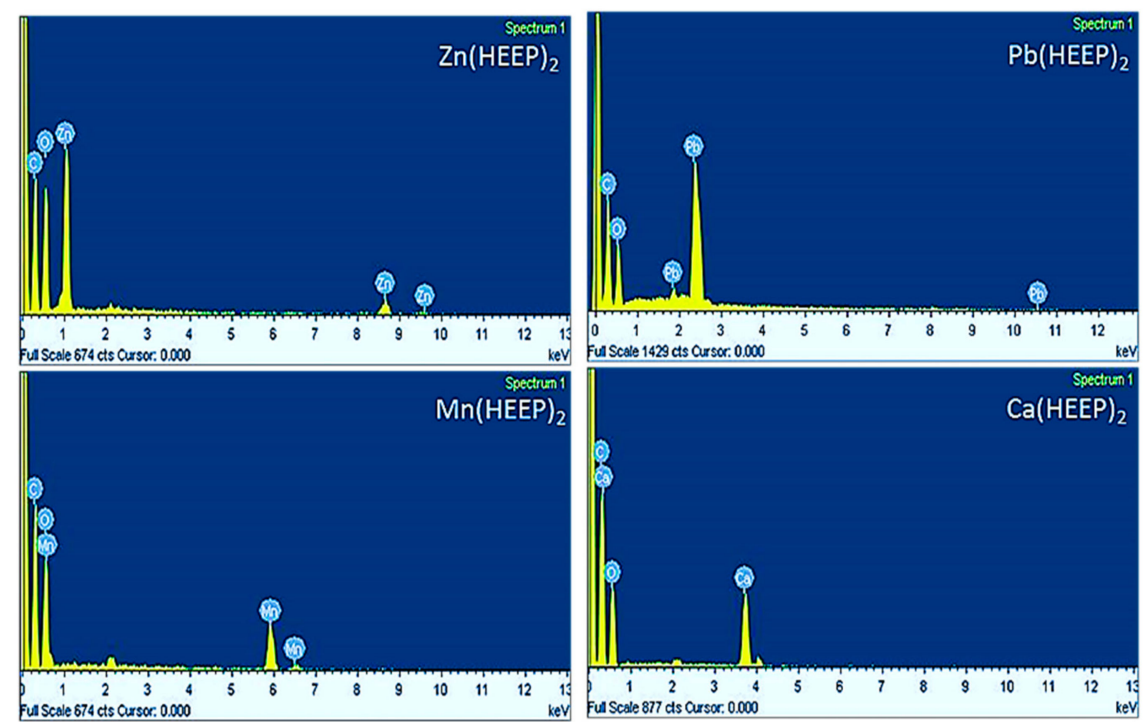

Figure 6. EDS spectra of $\mathrm{M}(\mathrm{HEEP})_{2}(\mathrm{M}=\mathrm{Zn}, \mathrm{Mn}, \mathrm{Pb}$, and $\mathrm{Ca})$. 


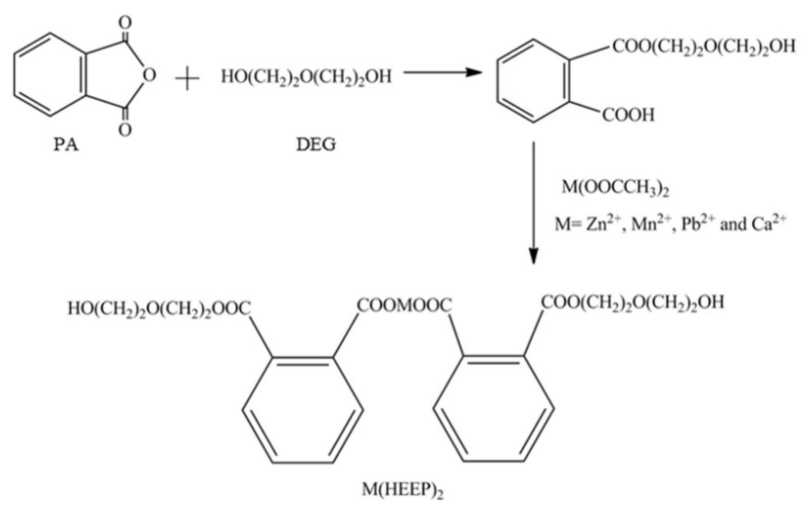

Scheme 1. Manufacture process of the $\mathrm{M}(\mathrm{HEEP}) 2(\mathrm{M}=\mathrm{Zn}, \mathrm{Mn}, \mathrm{Pb}$, and $\mathrm{Ca})$.

\subsection{Antibacterial Activity of $M(H E E P)_{2}$-Containing WUO Coatings}

In this study, the WUO coatings with hexamethylene diisocyanate (HDI) and isophorone diisocyanate (IPDI), and dimethylolpropionic acid at $\mathrm{NCO} / \mathrm{OH}$ molars of 0.9 were used, which were, respectively, named the HDI-0.9 coating and IPDI-0.9 coating. The bacteria including E. coli (Gram-negative bacterium) and S. aureus (Gram-positive bacterium) were used and the agar disk diffusion method was applied for determining the antibacterial activity. The antibacterial activity of various $\mathrm{M}(\mathrm{HEEP})_{2}(\mathrm{M}=\mathrm{Zn}, \mathrm{Mn}, \mathrm{Pb}$, and $\mathrm{Ca})$ and commercial nanoAg dosages containing WUO films synthesizing with HDI and IPDI for E. coli are listed in Tables 2 and 3, respectively, and the inhibitory zone of $\mathrm{Zn}(\mathrm{HEEP})_{2}$ for $E$. coli that was used as an example is presented in Figure 7. The results showed that the inhibitory zone of the blank group (WUO films containing $\left.0 \mathrm{phr} \mathrm{Zn}(\mathrm{HEEP})_{2}\right)$ ) was $8 \mathrm{~mm}$ (Figure 7a), meaning inactive on antibacterial activity, while the inhibitory zone increased to $15 \mathrm{~mm}$ (as shown in Figure $7 \mathrm{~b}$ ) with increasing $\mathrm{Zn}(\mathrm{HEEP})_{2}$ dosage of $2.0 \mathrm{phr}$, assigning mildly active antibacterial activity. However, the inhibitory zone decreased to $11 \mathrm{~mm}$ with increasing the $\mathrm{Zn}(\mathrm{HEEP})_{2}$ content to $4.0 \mathrm{phr}$ (Figure 7c). The Table 2 showed that in the HDI- 0.9 coating, except the $\mathrm{Zn}(\mathrm{HEEP})_{2}$ must add to $0.6 \mathrm{phr}$, the other $\mathrm{M}(\mathrm{HEEP})_{2}((\mathrm{M}=\mathrm{Mn}, \mathrm{Pb}$, and $\mathrm{Ca})$ and commercial nanoAg had only the dosage of $0.2 \mathrm{phr}$ had promptly a mildly active antibacterial activity for $E$. coli.
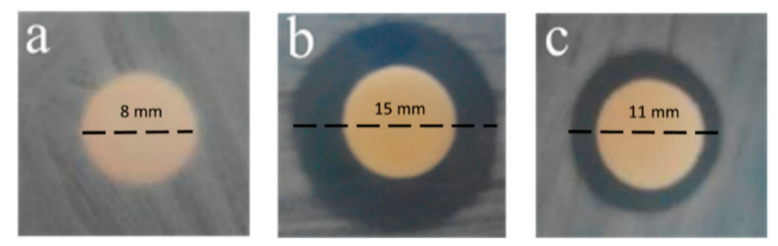

Figure 7. Inhibitory zone of E. coli of adding (a) $0 \mathrm{phr}$, (b) $2.0 \mathrm{phr}$, and (c) $4.0 \mathrm{phr} \mathrm{Zn}(\mathrm{HEEP})_{2}$ into waterborne urethane oil (WUO) films.

Table 3 for IPDI- 0.9 coatings, the inhibitory zone of without $\mathrm{M}(\mathrm{HEEP})_{2}$ was $8 \mathrm{~mm}$, indicating inactive antibacterial activity for E. coli. The $\mathrm{Zn}(\mathrm{HEEP})_{2}$ containing WUO film had a superior antibacterial activity, its inhibitory zones increased from 11 to $14 \mathrm{~mm}$ with an increasing dosage of 0.2-1.0 phr. The inhibitory zones of $\mathrm{Mn}(\mathrm{HEEP})_{2}$ containing WUO films were $10-11 \mathrm{~mm}$, also assigning a mildly active, but they show less efficiency on antibacterial activity than the Zn(HEEP $)_{2}$ containing WUO films. In addition, the $\mathrm{Pb}(\mathrm{HEEP})_{2}$ and $\mathrm{Ca}(\mathrm{HEEP})_{2}$ containing WUO films (IPDI-Pb and IPDI-Ca) had inactive antibacterial activity for E. coli. However, the control group of commercial nanoAg containing WUO films (IPDI-Ag) possessed inhibitory zones of 19-23 $\mathrm{mm}$ and had the highest antibacterial activity for $E$. coli. Even though by only adding $0.2 \mathrm{phr}$ of nanoAg, it shows a highly active antibacterial activity. 
Table 2. Inhibitory zone of various $\mathrm{M}(\mathrm{HEEP})_{2}(\mathrm{M}=\mathrm{Zn}, \mathrm{Mn}, \mathrm{Pb}$, and $\mathrm{Ca})$ and commercial nanoAg dosages containing WUO films synthesizing with HDI for E. coli.

\begin{tabular}{cccccc}
\hline Dosage (phr) $^{\mathbf{a}}$ & HDI-Zn $^{\mathbf{b}}$ & HDI-Mn & HDI-Pb & HDI-Ca & HDI-Ag $^{\mathbf{c}}$ \\
\hline 0.0 & $-(8 \pm 0)$ & $-(8 \pm 0)$ & $-(8 \pm 0)$ & $-(8 \pm 0)$ & $-(8 \pm 0)$ \\
0.2 & $-(8 \pm 1)$ & $+(12 \pm 0)$ & $+(11 \pm 1)$ & $+(11 \pm 0)$ & $+(10 \pm 1)$ \\
0.4 & $-(9 \pm 1)$ & $+(11 \pm 1)$ & $+(11 \pm 1)$ & $+(10 \pm 0)$ & $+(10 \pm 1)$ \\
0.6 & $+(10 \pm 1)$ & $+(11 \pm 0)$ & $+(12 \pm 1)$ & $+(10 \pm 0)$ & $-(9 \pm 1)$ \\
0.8 & $+(11 \pm 1)$ & $+(10 \pm 1)$ & $+(12 \pm 1)$ & $+(10 \pm 0)$ & $+(10 \pm 1)$ \\
1.0 & $+(13 \pm 1)$ & $+(11 \pm 0)$ & $+(10 \pm 1)$ & $+(10 \pm 1)$ & $+(10 \pm 1)$ \\
2.0 & $+(15 \pm 0)$ & $+(11 \pm 0)$ & $+(10 \pm 0)$ & $-(9 \pm 1)$ & $+(10 \pm 1)$ \\
4.0 & $+(11 \pm 1)$ & $+(11 \pm 1)$ & $+(12 \pm 1)$ & $+(10 \pm 0)$ & $+(12 \pm 1)$ \\
\hline
\end{tabular}

- inactive $(0-9 \mathrm{~mm}) ;+$ mildly active $(10-15 \mathrm{~mm}) ;++$ moderately active $(16-20 \mathrm{~mm})$; and +++ highly active $(\geq 21 \mathrm{~mm})$. ${ }^{a} \mathrm{M}(\mathrm{HEEP})_{2}(\mathrm{M}=\mathrm{Zn}, \mathrm{Mn}, \mathrm{Pb}$, and $\mathrm{Ca})$ or commercial nanoAg contents by the solid content of WUO coating.

${ }^{\mathrm{b}}$ HDI-0.9 coating contains $\mathrm{Zn}(\mathrm{HEEP})_{2} .{ }^{\mathrm{c}}$ commercial nanoAg.

Table 3. Inhibitory zone of various $\mathrm{M}(\mathrm{HEEP})_{2}(\mathrm{M}=\mathrm{Zn}, \mathrm{Mn}, \mathrm{Pb}$, and $\mathrm{Ca})$ dosages containing of WUO films synthesizing with IPDI for E. coli.

\begin{tabular}{cccccc}
\hline Dosage (phr) $^{\mathbf{a}}$ & IPDI-Zn $^{\mathbf{b}}$ & IPDI-Mn & IPDI-Pb & IPDI-Ca & IPDI-Ag $^{\mathbf{c}}$ \\
\hline 0.0 & $-(8 \pm 0)$ & $-(8 \pm 0)$ & $-(8 \pm 0)$ & $-(8 \pm 0)$ & $-(8 \pm 0)$ \\
0.2 & $+(11 \pm 1)$ & $+(11 \pm 0)$ & $-(8 \pm 0)$ & $-(8 \pm 0)$ & $+++(21 \pm 1)$ \\
0.4 & $+(13 \pm 0)$ & $+(11 \pm 1)$ & $-(8 \pm 0)$ & $-(8 \pm 0)$ & $+++(21 \pm 1)$ \\
0.6 & $+(13 \pm 1)$ & $+(11 \pm 0)$ & $-(8 \pm 0)$ & $-(8 \pm 0)$ & $++(20 \pm 1)$ \\
0.8 & $+(13 \pm 1)$ & $+(11 \pm 1)$ & $-(8 \pm 0)$ & $-(8 \pm 0)$ & $++(20 \pm 1)$ \\
1.0 & $+(14 \pm 0)$ & $+(10 \pm 1)$ & $-(8 \pm 0)$ & $-(8 \pm 0)$ & $++(19 \pm 2)$ \\
2.0 & $+(14 \pm 1)$ & $+(10 \pm 1)$ & $-(8 \pm 0)$ & $-(8 \pm 0)$ & $+++(22 \pm 1)$ \\
4.0 & $+(14 \pm 1)$ & $+(10 \pm 0)$ & $-(8 \pm 0)$ & $-(8 \pm 0)$ & $+++(23 \pm 2)$ \\
\hline
\end{tabular}

- inactive (0-9 $\mathrm{mm}) ;+$ mildly active $(10-15 \mathrm{~mm}) ;++$ moderately active $(16-20 \mathrm{~mm})$; and +++ highly active $(\geq 21 \mathrm{~mm})$. $a, b, c$ the same as the Table 2 .

The antibacterial activity of various $\mathrm{M}(\mathrm{HEEP})_{2}(\mathrm{M}=\mathrm{Zn}, \mathrm{Mn}, \mathrm{Pb}$, and $\mathrm{Ca})$ and commercial nanoAg dosage containing WUO films synthesizing with HDI and IPDI for S. aureus are listed in Tables 4 and 5, respectively. The results showed that the inhibitory zone of WUO films without $\mathrm{M}(\mathrm{HEEP})_{2}$ and commercial nanoAg was $9 \mathrm{~mm}$, meaning inactive antibacterial activity for S. aureus. The inhibitory zone of HDI-Zn, HDI-Mn, and HDI-Ca films were 11-14 mm, 12-14 mm, and 13-15 mm, respectively, assigning mildly active antibacterial activity. However, the HDI-Pb films had a larger inhibitory zone of $15-16 \mathrm{~mm}$, especially the ones of $0.4-1.0 \mathrm{phr}$ possessed a superior antibacterial activity, which was compared with the control group of HDI-Ag films, which the inhibitory zone was 18-19 $\mathrm{mm}$ and revealed a moderately active antibacterial activity for $S$. aureus.

Table 5 shows the IPDI- 0.9 coatings on antibacterial activity for $S$. aureus. The inhibitory zone of IPDI-Mn, IPDI-Pb, and IPDI-Ca were 12-14 mm, 12-14mm, and 11-13 mm, respectively, indicating a mildly active on antibacterial activity for $S$. aureus. However, the $\mathrm{Zn}(\mathrm{HEEP})_{2}$ containing WUO films had a larger inhibitory zone of $15-19 \mathrm{~mm}$, meaning a superior moderately active antibacterial activity, which was slightly less or equal to that of commercial nanoAg containing WUO films, which possessed a highly active antibacterial activity with a dosage of $0.8,1.0$, and $4.0 \mathrm{phr}$.

Integrating the results mentioned above, it could be concluded that except the IPDI-Pb and IPDI-Ca for E. coli, all of the WUO films with $\mathrm{M}(\mathrm{HEEP})_{2}$ had antibacterial activity for E. coli and S. aureus. Furthermore, the antibacterial efficiency for $S$. aureus was higher than that for E. coli. This might be due to the S. aureus belonging to Gram-positive bacterium, which the cell wall is composed of thickening peptidoglycan and takes a negative charge on the surface, which is more sensitivity to the metal ion with a positive charge than the Gram-negative bacterium of E. coli. In addition, the antibacterial efficiency of IPDI-Ag films was superior to that of HDI-Ag, which might be attributed to the IPDI- 0.9 coating having a larger particle size of the z-average diameter of $995 \mathrm{~nm}$ than the HDI-0.9 coating of $719 \mathrm{~nm}$ [21], 
and the nanoAg was easy and well dispersed in the waterborne IPDI-0.9 coating, on the contrary it was easy agglutinated in the HDI-0.9 coating, resulting in a less free Ag ion and leading to inferior antibacterial activity.

Table 4. Inhibitory zone of various $\mathrm{M}(\mathrm{HEEP})_{2}(\mathrm{M}=\mathrm{Zn}, \mathrm{Mn}, \mathrm{Pb}$, and $\mathrm{Ca})$ and commercial nanoAg dosages containing of WUO films synthesizing with HDI for $S$. aureus.

\begin{tabular}{cccccc}
\hline Dosage (phr) $^{\mathbf{a}}$ & HDI-Zn $^{\mathbf{b}}$ & HDI-Mn & HDI-Pb & HDI-Ca & HDI-Ag $^{\mathbf{c}}$ \\
\hline 0.0 & $-(9 \pm 1)$ & $-(9 \pm 1)$ & $-(9 \pm 1)$ & $-(9 \pm 1)$ & $-(9 \pm 1)$ \\
0.2 & $+(13 \pm 1)$ & $+(14 \pm 0)$ & $+(15 \pm 0)$ & $+(14 \pm 1)$ & $++(19 \pm 0)$ \\
0.4 & $+(11 \pm 0)$ & $+(14 \pm 0)$ & $++(16 \pm 0)$ & $+(14 \pm 1)$ & $++(19 \pm 1)$ \\
0.6 & $+(12 \pm 0)$ & $+(13 \pm 0)$ & $++(16 \pm 0)$ & $+(14 \pm 1)$ & $++(18 \pm 1)$ \\
0.8 & $+(12 \pm 0)$ & $+(12 \pm 0)$ & $++(16 \pm 1)$ & $+(13 \pm 1)$ & $++(18 \pm 1)$ \\
1.0 & $+(13 \pm 1)$ & $+(13 \pm 0)$ & $++(16 \pm 0)$ & $+(15 \pm 1)$ & $++(18 \pm 1)$ \\
2.0 & $+(13 \pm 0)$ & $+(12 \pm 0)$ & $+(15 \pm 1)$ & $+(15 \pm 1)$ & $++(18 \pm 1)$ \\
4.0 & $+(14 \pm 0)$ & $+(13 \pm 1)$ & $+(15 \pm 1)$ & $+(15 \pm 1)$ & $++(19 \pm 0)$ \\
\hline
\end{tabular}

- inactive $(0-9 \mathrm{~mm}) ;+$ mildly active $(10-15 \mathrm{~mm}) ;++$ moderately active $(16-20 \mathrm{~mm})$; and +++ highly active $(\geq 21 \mathrm{~mm})$. $a, b, c$ the same as the Table 2 .

Table 5. Inhibitory zone of various $\mathrm{M}(\mathrm{HEEP})_{2}(\mathrm{M}=\mathrm{Zn}, \mathrm{Mn}, \mathrm{Pb}$, and $\mathrm{Ca})$ and commercial nanoAg dosages containing of WUO films synthesizing with IPDI for $S$. aureus.

\begin{tabular}{cccccc}
\hline Dosage (phr) $^{\mathbf{a}}$ & IPDI-Zn $^{\mathbf{b}}$ & IPDI-Mn & IPDI-Pb & IPDI-Ca & IPDI-Ag $^{\mathbf{c}}$ \\
\hline 0.0 & $-(9 \pm 1)$ & $-(9 \pm 1)$ & $-(9 \pm 1)$ & $-(9 \pm 1)$ & $-(9 \pm 1)$ \\
0.2 & $+(15 \pm 2)$ & $+(14 \pm 0)$ & $+(12 \pm 1)$ & $+(11 \pm 0)$ & $++(20 \pm 1)$ \\
0.4 & $++(16 \pm 1)$ & $+(14 \pm 0)$ & $+(14 \pm 1)$ & $+(13 \pm 1)$ & $++(20 \pm 0)$ \\
0.6 & $++(17 \pm 1)$ & $+(13 \pm 0)$ & $+(13 \pm 1)$ & $+(12 \pm 1)$ & $++(18 \pm 1)$ \\
0.8 & $++(18 \pm 1)$ & $+(12 \pm 0)$ & $+(13 \pm 1)$ & $+(11 \pm 1)$ & $+++(24 \pm 1)$ \\
1.0 & $++(19 \pm 1)$ & $+(13 \pm 0)$ & $+(13 \pm 1)$ & $+(13 \pm 1)$ & $+++(29 \pm 1)$ \\
2.0 & $++(16 \pm 1)$ & $+(12 \pm 0)$ & $+(12 \pm 1)$ & $+(12 \pm 1)$ & $++(19 \pm 1)$ \\
4.0 & $++(17 \pm 0)$ & $+(13 \pm 1)$ & $+(12 \pm 2)$ & $+(12 \pm 1)$ & $+++(21 \pm 1)$ \\
\hline
\end{tabular}

- inactive (0-9 $\mathrm{mm}) ;+$ mildly active $(10-15 \mathrm{~mm}) ;++$ moderately active $(16-20 \mathrm{~mm})$; and +++ highly active $(\geq 21 \mathrm{~mm})$. $a, b, c$ the same as the Table 2 .

\subsection{Antifungal Activity of $M(H E E P)_{2}$-Containing WUO Coatings}

In this study, the fungi including brown-rot fungus of G. trabeum and white-rot fungus of L. betulina were used and the agar disk diffusion method was applied for determining the antifungal activity. The antifungal activity of various $\mathrm{M}(\mathrm{HEEP})_{2}(\mathrm{M}=\mathrm{Zn}, \mathrm{Mn}, \mathrm{Pb}$, and $\mathrm{Ca})$ and commercial nanoAg dosages containing WUO films synthesizing with HDI and IPDI for G. trabeum are listed in Tables 6 and 7, respectively. The results showed that the inhibitory zone of blank group ( $0 \mathrm{phr}$ ) was $8 \mathrm{~mm}$, meaning inactive antifungal activity for G. trabeum. The WUO films with HDI and containing M(HEEP) including HDI-Zn, HDI-Mn, HDI-Pb, HDI-Ca, and commercial nanoAg (HDI-Ag) had the inhibitory zone of 11-13 mm, 9-12 mm, 11-13 mm, 9-11 mm, and 10-11 mm, respectively, revealing only a dosage of $0.2 \mathrm{phr}$ had mildly active antifungal activity for G. trabeum. Furthermore, even though the HDI-0.9 films with antimicrobial agents attributed to mildly active antifungal activity, the HDI-Zn and HDI-Pb exhibiting a superior antifungal efficiency compared to HDI-Ag.

The IPDI-0.9 films with antimicrobial agents (as shown in Table 7) had similar results to the HDI-0.9 films, especially the IPDI-Zn, IPDI-Mn, and IPDI-Ca with a dosage of $0.2 \mathrm{phr}$ had a higher antifungal activity for G. trabeum than IPDI-Ag and that of HDI-0.9 films. In particular the inhibitory zone of IPDI-Mn was $16 \mathrm{~mm}$, assigning a moderately active grade. 
Table 6. Inhibitory zone of various $\mathrm{M}(\mathrm{HEEP})_{2}(\mathrm{M}=\mathrm{Zn}, \mathrm{Mn}, \mathrm{Pb}$, and $\mathrm{Ca})$ and commercial nanoAg dosages containing of WUO films synthesizing with HDI for G. trabeum.

\begin{tabular}{cccccc}
\hline Dosage (phr) $^{\mathbf{a}}$ & HDI-Zn $^{\mathbf{b}}$ & HDI-Mn & HDI-Pb & HDI-Ca & HDI-Ag $^{\mathbf{c}}$ \\
\hline 0.0 & $-(8 \pm 0)$ & $-(8 \pm 0)$ & $-(8 \pm 0)$ & $-(8 \pm 0)$ & $-(8 \pm 0)$ \\
0.2 & $+(11 \pm 0)$ & $+(12 \pm 1)$ & $+(12 \pm 0)$ & $+(11 \pm 0)$ & $+(10 \pm 0)$ \\
0.4 & $+(11 \pm 0)$ & $+(10 \pm 0)$ & $+(12 \pm 0)$ & $+(10 \pm 0)$ & $+(11 \pm 0)$ \\
0.6 & $+(12 \pm 0)$ & $-(9 \pm 0)$ & $+(12 \pm 0)$ & $+(10 \pm 0)$ & $+(11 \pm 0)$ \\
0.8 & $+(11 \pm 0)$ & $+(10 \pm 0)$ & $+(13 \pm 0)$ & $-(9 \pm 0)$ & $+(10 \pm 0)$ \\
1.0 & $+(12 \pm 0)$ & $+(10 \pm 1)$ & $+(12 \pm 0)$ & $-(9 \pm 1)$ & $+(10 \pm 0)$ \\
2.0 & $+(12 \pm 0)$ & $+(10 \pm 1)$ & $+(11 \pm 1)$ & $-(9 \pm 0)$ & $+(11 \pm 0)$ \\
4.0 & $+(13 \pm 0)$ & $+(11 \pm 1)$ & $+(13 \pm 0)$ & $+(11 \pm 0)$ & $+(10 \pm 0)$ \\
\hline
\end{tabular}

- inactive (0-9 $\mathrm{mm}) ;+$ mildly active $(10-15 \mathrm{~mm}) ;++$ moderately active $(16-20 \mathrm{~mm}) ;$ and +++ highly active $(\geq 21 \mathrm{~mm})$. $\mathrm{a}, \mathrm{b}, \mathrm{c}$ the same as the Table 2 .

Table 7. Inhibitory zone of various $\mathrm{M}(\mathrm{HEEP})_{2}(\mathrm{M}=\mathrm{Zn}, \mathrm{Mn}, \mathrm{Pb}$, and $\mathrm{Ca})$ and commercial nanoAg dosages containing of WUO films synthesizing with IPDI for G. trabeum.

\begin{tabular}{cccccc}
\hline Dosage (phr) $^{\mathbf{a}}$ & IPDI-Zn $^{\mathbf{b}}$ & IPDI-Mn & IPDI-Pb & IPDI-Ca & IPDI-Ag $^{\mathbf{c}}$ \\
\hline 0.0 & $-(8 \pm 0)$ & $-(8 \pm 0)$ & $-(8 \pm 0)$ & $-(8 \pm 0)$ & $-(8 \pm 0)$ \\
0.2 & $+(15 \pm 1)$ & $++(16 \pm 0)$ & $+(11 \pm 0)$ & $+(14 \pm 0)$ & $+(11 \pm 1)$ \\
0.4 & $+(13 \pm 0)$ & $+(15 \pm 0)$ & $+(11 \pm 1)$ & $+(11 \pm 0)$ & $+(11 \pm 0)$ \\
0.6 & $+(13 \pm 0)$ & $+(13 \pm 0)$ & $+(11 \pm 0)$ & $+(11 \pm 0)$ & $+(12 \pm 0)$ \\
0.8 & $+(12 \pm 0)$ & $+(14 \pm 0)$ & $+(11 \pm 0)$ & $+(11 \pm 0)$ & $+(12 \pm 1)$ \\
1.0 & $+(13 \pm 0)$ & $+(14 \pm 0)$ & $+(11 \pm 0)$ & $+(12 \pm 0)$ & $+(12 \pm 0)$ \\
2.0 & $+(13 \pm 0)$ & $+(12 \pm 1)$ & $+(11 \pm 0)$ & $+(12 \pm 0)$ & $+(11 \pm 1)$ \\
4.0 & $+(13 \pm 0)$ & $+(14 \pm 0)$ & $+(10 \pm 0)$ & $+(15 \pm 1)$ & $+(11 \pm 2)$ \\
\hline
\end{tabular}

- inactive $(0-9 \mathrm{~mm}) ;+$ mildly active $(10-15 \mathrm{~mm}) ;++$ moderately active $(16-20 \mathrm{~mm})$; and +++ highly active $(\geq 21 \mathrm{~mm})$. $\mathrm{a}, \mathrm{b}, \mathrm{c}$ the same as the Table 2.

The antifungal activity of various $\mathrm{M}(\mathrm{HEEP})_{2}(\mathrm{M}=\mathrm{Zn}, \mathrm{Mn}, \mathrm{Pb}$, and $\mathrm{Ca})$ and commercial nanoAg dosages containing WUO films synthesizing with HDI and IPDI for white-rot fungus of L. betulina are listed in Tables 8 and 9, respectively. The results indicated that among all of the WUO films, the HDI-Zn had the best antifungal activity for L. betulina, but the dosage of $\mathrm{Zn}(\mathrm{HEEP})_{2}$ must exceed $1.0 \mathrm{phr}$. In addition to this, the HDI-Mn, HDI-Pb, HDI-Ca, and control HDI-Ag had almost inactive antifungal activity for L. betulina. The IPDI-0.9 films had similar results to HDI-0.9 films, only the IPDI-Zn with a dosage of $4.0 \mathrm{phr}$ had an inhibitory zone of $13 \mathrm{~mm}$, assigning a mildly active antifungal activity.

Table 8. Inhibitory zone of various $\mathrm{M}(\mathrm{HEEP})_{2}(\mathrm{M}=\mathrm{Zn}, \mathrm{Mn}, \mathrm{Pb}$, and $\mathrm{Ca})$ and commercial nanoAg dosages containing of WUO films synthesizing with HDI for L. betulina.

\begin{tabular}{cccccc}
\hline Dosage (phr) $^{\mathbf{a}}$ & HDI-Zn $^{\mathbf{b}}$ & HDI-Mn & HDI-Pb & HDI-Ca & HDI-Ag $^{\mathbf{c}}$ \\
\hline 0.0 & $-(8 \pm 0)$ & $-(8 \pm 0)$ & $-(8 \pm 0)$ & $-(8 \pm 0)$ & $-(8 \pm 0)$ \\
0.2 & $-(9 \pm 0)$ & $-(8 \pm 0)$ & $-(9 \pm 1)$ & $-(8 \pm 0)$ & $-(8 \pm 0)$ \\
0.4 & $+(11 \pm 1)$ & $-(9 \pm 1)$ & $-(9 \pm 1)$ & $-(8 \pm 0)$ & $-(8 \pm 1)$ \\
0.6 & $-(9 \pm 1)$ & $+(11 \pm 1)$ & $-(9 \pm 1)$ & $-(8 \pm 1)$ & $-(8 \pm 1)$ \\
0.8 & $-(9 \pm 1)$ & $-(9 \pm 1)$ & $-(9 \pm 1)$ & $-(8 \pm 0)$ & $-(9 \pm 1)$ \\
1.0 & $+(13 \pm 1)$ & $-(9 \pm 1)$ & $-(8 \pm 0)$ & $-(8 \pm 1)$ & $-(8 \pm 1)$ \\
2.0 & $+(15 \pm 0)$ & $-(8 \pm 1)$ & $-(9 \pm 1)$ & $-(8 \pm 1)$ & $-(9 \pm 1)$ \\
4.0 & $+(15 \pm 1)$ & $+(10 \pm 1)$ & $+(11 \pm 0)$ & $-(9 \pm 1)$ & $-(8 \pm 1)$ \\
\hline
\end{tabular}

- inactive (0-9 mm); + mildly active (10-15 $\mathrm{mm}) ;++$ moderately active $(16-20 \mathrm{~mm})$; and +++ highly active $(\geq 21 \mathrm{~mm})$. $a, b, c$ the same as the Table 2 . 
Table 9. Inhibitory zone of various $\mathrm{M}(\mathrm{HEEP})_{2}(\mathrm{M}=\mathrm{Zn}, \mathrm{Mn}, \mathrm{Pb}$, and $\mathrm{Ca})$ and commercial nanoAg dosages containing of WUO films synthesizing with IPDI for L. betulina.

\begin{tabular}{cccccc}
\hline Dosage (phr) $^{\mathbf{a}}$ & IPDI-Zn $^{\mathbf{b}}$ & IPDI-Mn & IPDI-Pb & IPDI-Ca & IPDI-Ag $^{\mathbf{c}}$ \\
\hline 0.0 & $-(8 \pm 0)$ & $-(8 \pm 0)$ & $-(8 \pm 0)$ & $-(8 \pm 0)$ & $-(8 \pm 0)$ \\
0.2 & $-(8 \pm 1)$ & $-(8 \pm 1)$ & $-(8 \pm 0)$ & $-(8 \pm 0)$ & $-(8 \pm 0)$ \\
0.4 & $-(8 \pm 1)$ & $-(8 \pm 1)$ & $-(8 \pm 1)$ & $-(9 \pm 1)$ & $-(8 \pm 1)$ \\
0.6 & $-(8 \pm 1)$ & $-(9 \pm 1)$ & $-(8 \pm 1)$ & $-(8 \pm 0)$ & $-(8 \pm 1)$ \\
0.8 & $-(9 \pm 0)$ & $-(9 \pm 0)$ & $-(8 \pm 1)$ & $-(9 \pm 1)$ & $-(8 \pm 1)$ \\
1.0 & $-(9 \pm 1)$ & $+(10 \pm 1)$ & $+(10 \pm 1)$ & $-(9 \pm 1)$ & $-(9 \pm 1)$ \\
2.0 & $-(9 \pm 1)$ & $-(9 \pm 1)$ & $-(8 \pm 1)$ & $-(8 \pm 1)$ & $-(8 \pm 1)$ \\
4.0 & $+(13 \pm 0)$ & $-(9 \pm 1)$ & $-(9 \pm 1)$ & $-(8 \pm 0)$ & $-(8 \pm 0)$ \\
\hline
\end{tabular}

- inactive $(0-9 \mathrm{~mm}) ;+$ mildly active $(10-15 \mathrm{~mm}) ;++$ moderately active $(16-20 \mathrm{~mm})$; and +++ highly active $(\geq 21 \mathrm{~mm})$. $\mathrm{a}, \mathrm{b}, \mathrm{c}$ the same as the Table 2 .

From the results of antimicrobial activity, it can be seen that the metal-containing WUO films had more efficiency on antibacterial activity for bacterial than on antifungal activity for fungi. This may be attributed to the metal ions that can directly and easily damage the bacterial cell wall, by release of ions followed by an increased membrane permeability, loss of the proton motive force, and efflux of intracellular components [30]. The mechanism of metal ions on inhibiting microbial growth is an interesting topic and will be studied in the future.

\subsection{Film Properties of WUO Coatings}

In the present study, the $\mathrm{M}(\mathrm{HEEP})_{2}(\mathrm{M}=\mathrm{Zn}, \mathrm{Mn}, \mathrm{Pb}$, and $\mathrm{Ca})$ were additives for antimicrobial agents. Even though the results revealed that the WUO film synthesizing with HDI films containing $\mathrm{Zn}(\mathrm{HEEP})_{2}$ of $2.0 \mathrm{phr}$ and $\mathrm{Pb}(\mathrm{HEEP})_{2}$ of $0.4 \mathrm{phr}$ had the best antibacterial activity for E. coli and S. aureus, respectively. The IPDI films containing $\mathrm{Zn}(\mathrm{HEEP})_{2}$ of $1.0 \mathrm{phr}$ had the best antibacterial activity for both E. coli and S. aureus. For antifungal activity, the WUO film synthesizing with HDI films containing $\mathrm{Pb}(\mathrm{HEEP})_{2}$ of $0.8 \mathrm{phr}$ and $\mathrm{Zn}(\mathrm{HEEP})_{2}$ of $2.0 \mathrm{phr}$ as well as IPDI films containing $\mathrm{Mn}(\mathrm{HEEP})_{2}$ of $0.2 \mathrm{phr}$ and $\mathrm{Zn}(\mathrm{HEEP})_{2}$ of $4.0 \mathrm{phr}$ had the best performances against G. trabeum and L. betulina, respectively. From the results mentioned above it also shows that the WUO films of HDI-Pb and IPDI-Zn, which were synthesized with HDI and IPDI, respectively, had the best antimicrobial efficiency for bacteria and fungi used in the study. According to the antimicrobial activity grades, the dosage of $\mathrm{Zn}(\mathrm{HEEP})_{2}$ and $\mathrm{Pb}(\mathrm{HEEP})_{2}$ was only $0.2 \mathrm{phr}$, which exhibited superiority of antimicrobial activity. Therefore, in this section, the films properties of HDI-0.9 (0.0 phr), HDI-Pb (0.2 phr), HDI-Ag (0.2 phr as control group), IPDI-0.9, IPDI-Zn, and IPDI-Ag were compared. The results are listed in Table 10.

The WUO film of IPDI- 0.9 had a higher hardness of $87 \mathrm{sec}$ than HDI- 0.9 of $13 \mathrm{sec}$, while the hardness of metal-containing WUO films decreased slightly by adding the $\mathrm{Zn}(\mathrm{HEEP})_{2}, \mathrm{~Pb}(\mathrm{HEEP})_{2}$, and nanoAg, which was from 13 to $11 \mathrm{sec}$ for HDI films and from 87 to $72-76 \mathrm{sec}$ for IPDI films. The IPDI film had a higher hardness than the HDI film. The results were also confirmed by the studies of Chang et al. [22]. The impact resistance of all HDI films was $25 \mathrm{~cm}$, but of all IPDI films was lower than $5 \mathrm{~cm}$. The bending resistance of all HDI films was lower than $2 \mathrm{~mm}$-diameters and was superior to all IPDI films of $10 \mathrm{~mm}$-diameter steel shaft. The results demonstrated that there had no difference between with or without metal-containing and kinds of metal ions on the impact and bending resistance of the WUO films. In addition, due to having a long alkyl structure for HDI films, it had a lower hardness, higher impact, and bending resistance than IPDI films with a hard and brittle alicyclic structure. However, all of the films showed an excellent adhesion of 10 grades on wood, exhibiting that the WUO coating was suitable for wood finishing. The mass retention of HDI-0.9 was $75.0 \%$, which increased slightly for HDI-Zn and HDI-Ag of $77.4 \%$ and $77.1 \%$, respectively. The similar result could also be found in IPDI-films. While, the HDI films had a higher mass retention than IPDI films, it may be due to the molecular weight of HDI $(\mathrm{Mw}=10,734)$ being higher than that of IPDI (Mw $=6126)$ [21], and the steric effect of IPDI hindering the oxidative polymerization of unsaturated fatty acids in linseed 
oil [31]. The $60^{\circ}$ gloss of HDI- 0.9 had a value of $78 \%$, whereas the HDI-Pb showed a decrease to $62 \%$ and an HDI-Ag increase to $81 \%$. The results may be attributed to the $\mathrm{Zn}(\mathrm{HEEP})_{2}$ and $\mathrm{Pb}(\mathrm{HEEP})_{2}$ having a larger particle diameter than nanoAg. Similar results were also shown in IPDI films, but were exhibited at lower gloss values.

Table 10. Properties of antimicrobial WUO films synthesizing with HDI and IPDI.

\begin{tabular}{ccccccc}
\hline Property & HDI-0.9 $^{\mathbf{a}}$ & HDI-Pb $^{\mathbf{b}}$ & HDI-Ag $^{\mathbf{b}}$ & IPDI-0.9 $^{\mathbf{a}}$ & IPDI-Zn $^{\mathbf{b}}$ & IPDI-Ag $^{\mathbf{b}}$ \\
\hline Hardness (König, sec) & $13 \pm 1$ & $11 \pm 1$ & $11 \pm 0$ & $87 \pm 2$ & $72 \pm 1$ & $76 \pm 1$ \\
Impact resistance (cm) & 25 & 25 & 25 & $<5$ & $<5$ & $<5$ \\
Bending resistance (mm) & $<2$ & $<2$ & $<2$ & 10 & 10 & 10 \\
Adhesion (grade) & 10 & 10 & 10 & 10 & 10 & 10 \\
Mass retention (\%) & $75.0 \pm 1.0$ & $77.4 \pm 0.5$ & $77.1 \pm 1.6$ & $65.3 \pm 1.3$ & $66.2 \pm 1.0$ & $67.8 \pm 1.2$ \\
$60^{\circ}$ Gloss (\%) & 78 & 62 & 81 & 47 & 32 & 52 \\
\hline
\end{tabular}

${ }^{\mathrm{a}}$ The films without an antimicrobial agent. ${ }^{\mathrm{b}}$ The films containing $0.2 \mathrm{phr}$ of an antimicrobial agent.

The lightfastness of antimicrobial WUO films synthesizing with HDI and IPDI before and after the color fading test are given in Figure 8 . The color difference $\left(\Delta \mathrm{E}^{*}\right)$ of WUO films increased with prolonged exposure under ultraviolet light irradiation, accounting for the color changes of the films, but the $\Delta \mathrm{E}^{*}$ values were found to stabilize at 16 days. The $\Delta \mathrm{E}^{*}$ values were $6.9,5.9$, and 6.8 for HDI-0.9, HDI-Pb, and HDI-Ag, and were 4.8, 5.5, and 4.9 for IPDI-0.9, IPDI-Zn, and IPDI-Ag, respectively, after ultraviolet light irradiation of 23 days. Generally speaking, it has no significant effect on the lightfastness of WUO films with adding antimicrobial agents. However, the IPDI films had a slight superiority in lightfastness over the HDI films, which all belonged to aliphatic isocyanates.
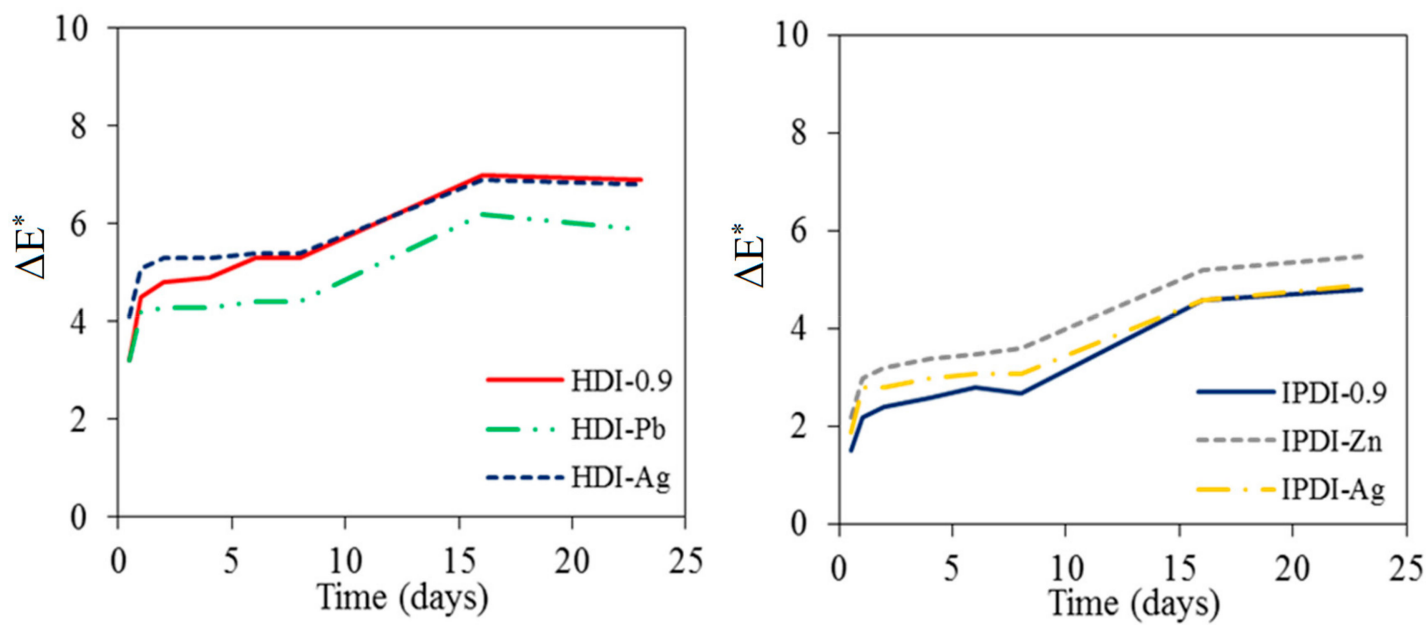

Figure 8. Time-dependent color difference $\left(\Delta \mathrm{E}^{*}\right)$ of antimicrobial WUO films under UV light irradiation.

The Tan $\delta$ curves of antimicrobial WUO films synthesizing with HDI and IPDI by a dynamic mechanical analysis (DMA) are given in Figures 9 and 10, respectively. The glass transition temperature $\left(T_{\mathrm{g}}\right)$ of HDI-0.9 film, which possessed a softer long alkyl chain, was $10.7^{\circ} \mathrm{C}$ and the IPDI-0.9 film, which possessed a harder alicyclic structure, was $55^{\circ} \mathrm{C}$. When adding the nanograde filler of the $\mathrm{Ag}$ ion, the $T_{\mathrm{g}}$ was shifted to a lower temperature, i.e., HDI-Ag was $6.2^{\circ} \mathrm{C}$ and IPDI-Ag was $49.3{ }^{\circ} \mathrm{C}$. This was attributed to an interfacial layer of polymer molecules whose chain relaxation dynamics were altered by the interaction with the filler surface. This is accompanied by a shift of the $T_{\mathrm{g}}$ itself to a lower temperature when the filler surface is organophilic [32]. However, for the micron-grade filler of $\mathrm{M}(\mathrm{HEEP})_{2}$, when adding the filler could change the $T_{\mathrm{g}}$ of the softer polymer such as the HDI film to a higher temperature, i.e., $\mathrm{HDI}-\mathrm{Pb}$ of $19.8^{\circ} \mathrm{C}$, whereas for the harder polymer such as the IPDI film to a lower temperature, i.e., IPDI-Zn of $39.1^{\circ} \mathrm{C}$ [32]. In addition, the IPDI-Zn had a phase separation, 
this may be due to the $\mathrm{Zn}(\mathrm{HEEP})_{2}$ agglutinated mainly in the hard segment of IPDI film located at the main $\alpha$ relaxation, the glass transition $T_{\mathrm{g}}$ of $39.1^{\circ} \mathrm{C}$, and a second relaxation occurred at $-17.9^{\circ} \mathrm{C}$ in the unfilled soft segment of the IPDI film.

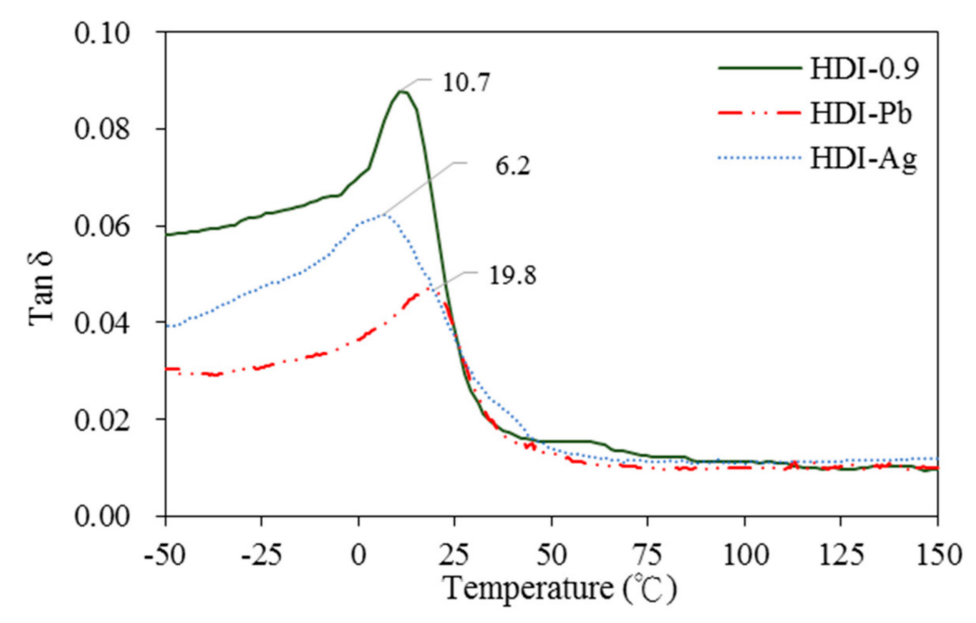

Figure 9. Tan $\delta$ curves of antimicrobial WUO films synthesizing with HDI.

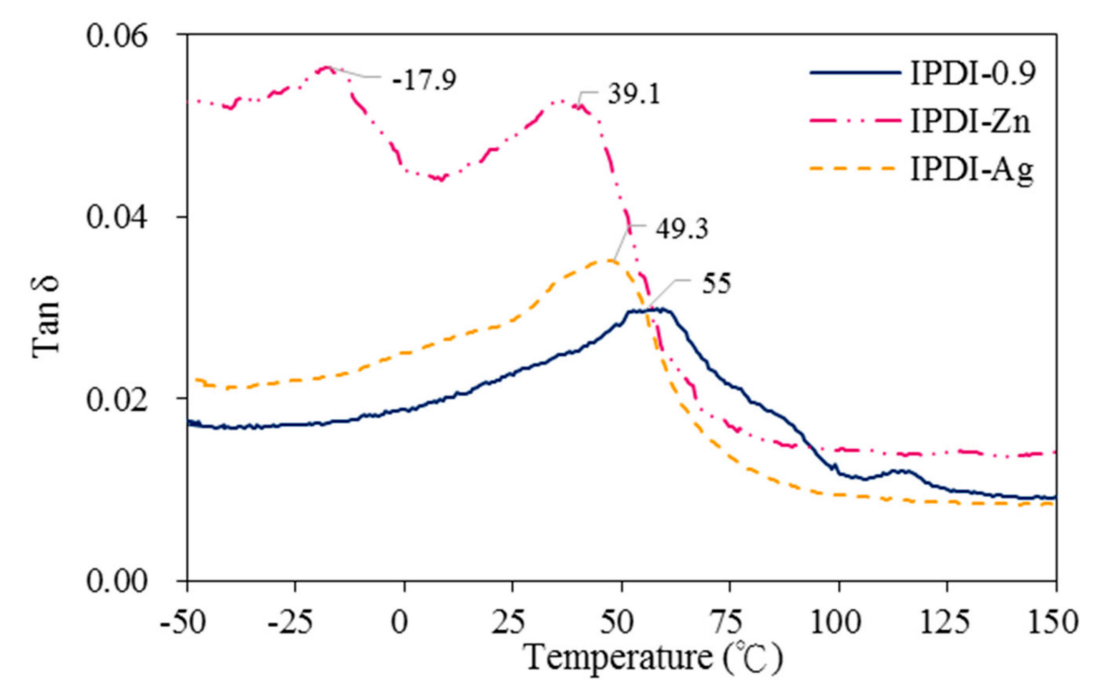

Figure 10. Tan $\delta$ curves of antimicrobial WUO films synthesizing with IPDI.

The TGA curves of antimicrobial WUO films synthesizing with HDI and IPDI are displayed by Figures 11 and 12, respectively. The WUO films with or without antimicrobial agents showed similar behavior of thermal degradation. They consisted of three dominant steps at around $250-350{ }^{\circ} \mathrm{C}$, $350-420^{\circ} \mathrm{C}$, and $420-500^{\circ} \mathrm{C}$, corresponding to the decomposition of the urethane linkage, the degradation of an aliphatic long chain of fatty acid from the linseed oil glyceride component, and the dehydrogenation and depolycondensation of alkyl groups, respectively [33-36]. The results showed that adding metal-containing antimicrobial agents can slightly enhance the thermal stability of the WUO films, e.g., the weight loss at $450{ }^{\circ} \mathrm{C}$ for HDI films were $73 \%, 69 \%$, and $71 \%$ of HDI- 0.9 , HDI-Pb, and HDI-Ag, respectively, and for IPDI films were $83 \%, 80 \%$, and $80 \%$ of IPDI- 0.9 , IPDI-Zn, and IPDI-Ag, respectively. The result also confirmed by the studies of Zafar et al. [11] and Chang and Chang [37]. In addition, the $\mathrm{M}(\mathrm{HEEP})_{2}$ and nanoAg containing WUO films had no significant difference in thermal stability. 


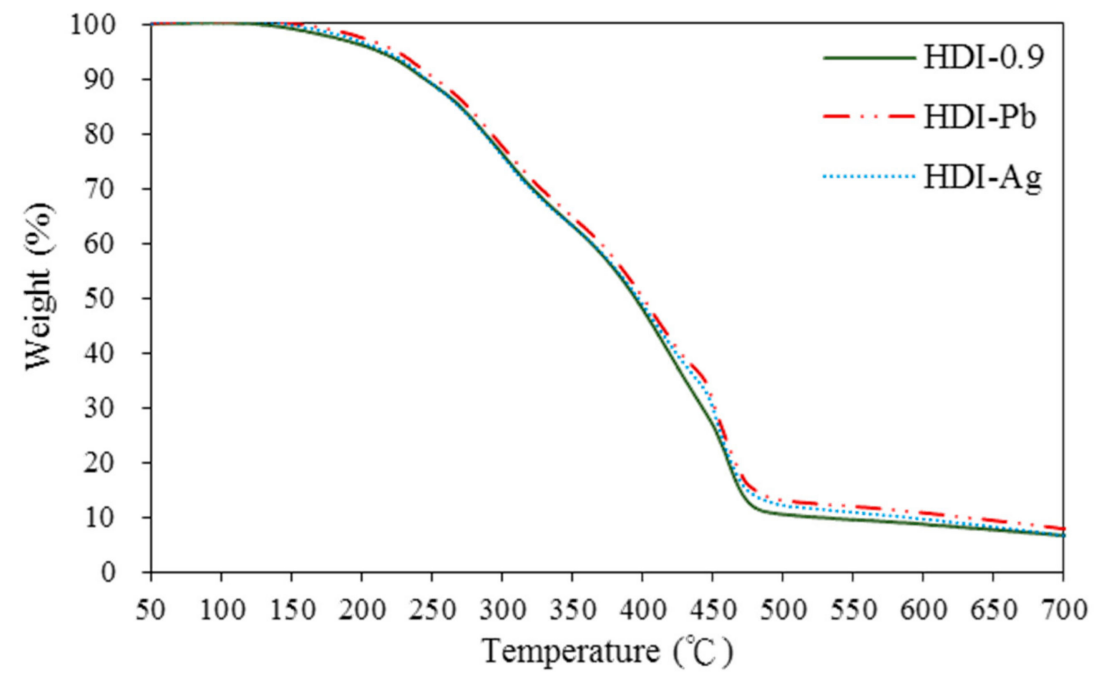

Figure 11. TGA curves of antimicrobial WUO films synthesizing with HDI.

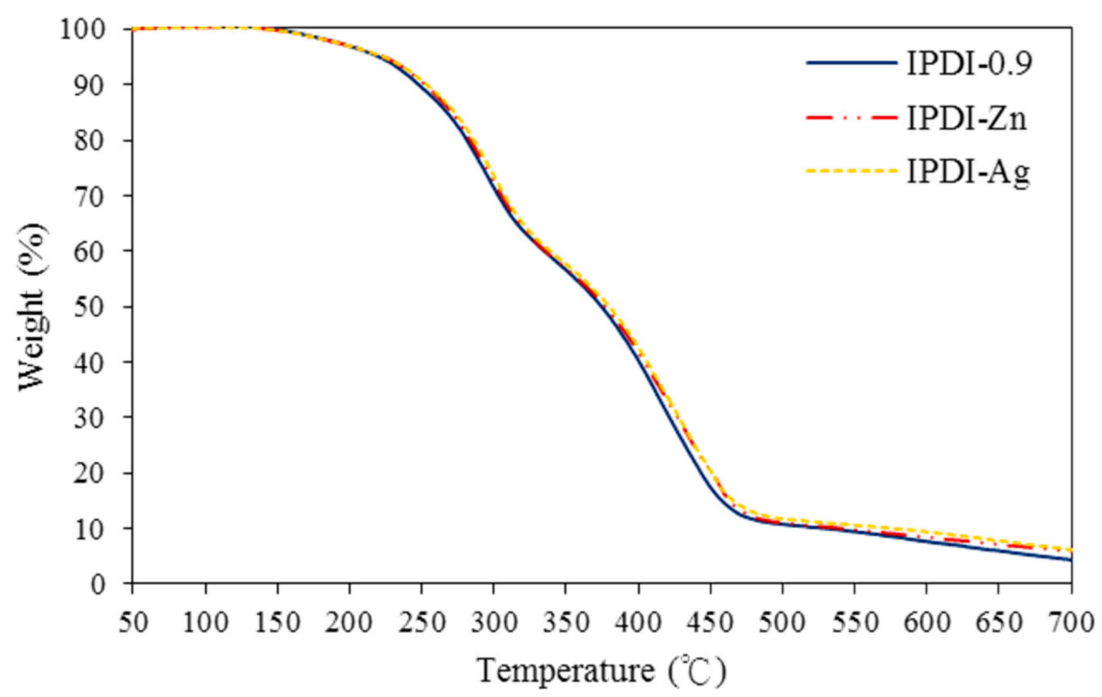

Figure 12. TGA curves of antimicrobial WUO films synthesizing with IPDI.

\section{Conclusions}

In the present study, the antimicrobial agents of mono(hydroxyethoxyethyl) phthalate $\mathrm{M}(\mathrm{HEEP})_{2}$ $(\mathrm{M}=\mathrm{Zn}, \mathrm{Mn}, \mathrm{Pb}$, and $\mathrm{Ca}$ ) powders could be readily synthesized and the yields were $43-55 \%$. The results of various antimicrobial agents and dosages on antimicrobial activity of WUO films showed that the WUO film synthesizing with HDI films containing $\mathrm{Zn}(\mathrm{HEEP})_{2}$ of $2.0 \mathrm{phr}$ and $\mathrm{Pb}(\mathrm{HEEP})_{2}$ of $0.4 \mathrm{phr}$ had the best antibacterial activity for E. coli and S. aureus, respectively. The IPDI films containing $\mathrm{Zn}(\mathrm{HEEP})_{2}$ of $1.0 \mathrm{phr}$ had the best antibacterial activity for both E. coli and S. aureus. For antifungal activity, the WUO film synthesizing with HDI films containing $\mathrm{Pb}(\mathrm{HEEP})_{2}$ of $0.8 \mathrm{phr}$ and $\mathrm{Zn}(\mathrm{HEEP})_{2}$ of $2.0 \mathrm{phr}$ as well as IPDI films containing Mn(HEEP $)_{2}$ of $0.2 \mathrm{phr}$ and $\mathrm{Zn}(\mathrm{HEEP})_{2}$ of $4.0 \mathrm{phr}$ had the best performances against $G$. trabeum and L. betulina, respectively. Comparing with commercial nanoAg powder, the $\mathrm{Zn}(\mathrm{HEEP})_{2}$ and $\mathrm{Pb}(\mathrm{HEEP})_{2}$ had a superior antifungal efficiency for brown-rot fungus of G. trabeum and white-rot fungus of L. betulina, while it had a slightly inferior efficiency in antibacterial activity for the Gram-negative bacterium of E. coli and Gram-positive bacterium of S. aureus. On the properties of WUO films, adding metal-containing antimicrobial agents could slightly enhance the thermal stability, but lowered the gloss of all films, however, the $T_{\mathrm{g}}$ value increased for the HDI film and decreased for the IPDI film. In addition, they had no significant difference in the film properties including hardness, impact resistance, bending resistance, adhesion, mass retention, and lightfastness between the WUO films with and without adding antimicrobial agents. 
Author Contributions: Conceptualization, K.-T.L.; Investigation, K.-T.L. and J.-P.C.; Methodology, J.-P.C.; Project administration, K.-T.L.; Resources, K.-T.L.; Software, J.-P.C.; Supervision, K.-T.L.; Writing—original draft, J.-P.C.; Writing-review and editing, K.-T.L. All authors have read and agreed to the published version of the manuscript.

Funding: This investigation was financially supported by the Ministry of Science and Technology (MOST), Taiwan.

Conflicts of Interest: The authors declare no conflict of interest.

\section{References}

1. Zhang, C.; Xia, Y.; Chen, R.; Huh, S.; Johnston, P.A.; Kessler, M.R. Soy-Castor Oil Based Polyols Prepared Using a Solvent-free and Catalyst-free Method and Polyurethanes. Therefrom. Green Chem. 2013, 15, 1477-1484. [CrossRef]

2. Xia, Y.; Larock, R.C. Vegetable Oil-based Polymeric Materials: Synthesis, Properties, and Applications. Green Chem. 2010, 12, 1893-1909. [CrossRef]

3. Veigel, S.; Lems, E.M.; Grüll, G.; Hansmann, C.; Rosenau, T.; Zimmermann, T.; Gindl-Altmutter, W. Simple Green Route to Performance Improvement of Fully Bio-Based Linseed Oil Coating Using Nanofibrillated Cellulose. Polymers 2017, 9, 425. [CrossRef] [PubMed]

4. Li, S.; Xu, C.; Yang, W.; Tang, Q. Thermoplastic Polyurethanes Stemming from Castor Oil: Green Synthesis and Their Application in Wood Bonding. Coatings 2017, 7, 159.

5. Ahn, B.K.; Kraft, S.; Wang, D.; Sun, X.S. Thermally Stable, Transparent, Pressure-Sensitive Adhesives from Epoxidized and Dihydroxyl Soybean Oil. Biomacromolecules 2011, 12, 1839-1843. [CrossRef] [PubMed]

6. Sharmin, E.; Zafar, F.; Akram, D.; Alam, M.; Ahmad, S. Recent Advances in Vegetable Oils Based Environment Friendly Coatings: A Review. Ind. Crops Prod. 2015, 76, 215-229. [CrossRef]

7. Zafar, F.; Ghosal, A.; Sharmin, E.; Chaturvedi, R.; Nishat, N. A Review on Cleaner Production of Polymeric and Nanocomposite Coatings Based on Waterborne Polyurethane Dispersions from Seed Oils. Prog. Org. Coat. 2019, 131, 259-275. [CrossRef]

8. Zafar, F.; Zafar, H.; Yaseen Shah, M.; Sharmin, E.; Ahmad, S. Vegetable Seed Oil Based Waterborne Polyesteramide: A "Green" Material. Chemistry of Phytopotentials: Health, Energy and Environmental Perspectives; Khemani, L.D., Srivastava, M.M., Srivastava, S., Eds.; Springer: Heidelberg, Germany, 2012; pp. 127-130.

9. Chen, Y.C.; Tai, W. Castor Oil-Based Polyurethane Resin for Low-Density Composites with Bamboo Charcoal. Polymers 2018, 10, 1100. [CrossRef]

10. Pfister, D.P.; Xia, Y.; Larock, R.C. Recent Advances in Vegetable Oil-Based Polyurethanes. ChemSusChem 2011, 4, 703-717. [CrossRef]

11. Zafar, F.; Ashraf, S.M.; Ahmad, S. Studies on Zinc-containing Linseed Oil Based Polyesteramide. React. Funct. Polym. 2007, 67, 928-935. [CrossRef]

12. Zafar, F.; Ashraf, S.M.; Ahmad, S. In Situ Development of Zn/Cd-Incorporated Poly(esteramide-urethane) from Renewable Resource. J. Appl. Polym. Sci. 2008, 110, 584-593. [CrossRef]

13. Zafar, F.; Zafar, H.; Sharmin, E.; Ahmad, S. Studies on Self Cured Zinc- Containing Pongamia Glabra Oil Based Polyesteramide. Prog. Org. Coat. 2010, 69, 517-521. [CrossRef]

14. Zafar, F.; Zafar, H.; Ashraf, S.M.; Sharmin, E. Studies on Ambient Cured Biobased Mn(II), Co(II) and Cu(II) Containing Metallopolyesteramides. J. Inorg. Organomet. Polym. Mater. 2011, 21, 646-654. [CrossRef]

15. Hsu, S.H.; Tseng, H.J.; Lin, Y.C. The Biocompatibility and Antibacterial Properties of Waterborne Polyurethane-silver Nanocomposites. Biomaterials 2010, 31, 6796-6808. [CrossRef] [PubMed]

16. Li, J.H.; Hong, R.Y.; Li, M.Y.H.; Li, Z.; Zheng, Y.; Ding, J. Effects of ZnO Nanoparticles on the Mechanical and Antibacterial Properties of Polyurethane Coatings. Prog. Org. Coat. 2009, 64, 504-509. [CrossRef]

17. Jayakumar, R.; Nanjundan, S.; Rajkumar, M.; Nagendran, R. Studies on Metal-containing Polyurethane Based on Divalent Metal Salts of Mono (hydroxylethoxyethyl)phthalate. J. Macromol. Sci. Pure Appl. Chem. 2007, 38, 869-888. [CrossRef]

18. Jayakumar, R.; Rajkumar, M.; Nagenran, R.; Nanjundan, S. Synthesis and Characterization of Metal-containing Polyurethane with Antibacterial Activity. J. Appl. Polym. Sci. 2002, 85, 1194-1206. [CrossRef]

19. Jayakumar, R.; Lee, Y.S.; Rajkumar, M.; Nanjundan, S. Synthesis, Characterization, and Antibacterial Activity of Metal-containing Polyurethanes. J. Appl. Polym. Sci. 2004, 91, 288-295. [CrossRef]

20. Matsuda, H. Synthesis of Polymers by Using Divalent Metal Salts of Mono(hydroxyethyl)phthalate: Metal-containing Polyurethanes. J. Polym. Sci. 1974, 12, 455-468. 
21. Chang, C.W.; Chang, J.P.; Lu, K.T. Synthesis of linseed oil-based waterborne urethane oil wood coatings. Polymers 2018, 10, 1235. [CrossRef]

22. Chang, J.P.; Chang, C.W.; Lu, K.T. Characteristic of Linseed Oil-based Waterborne Urethane Oil Wood Coatings. For. Prod. Ind. 2018, 37, 89-100.

23. CNS 9007 Method of Test for Paints-Sampling and General Condition; CNS: Taipei, Taiwan, 1995.

24. Alzoreky, N.S.; Nakahara, K. Antibacterial Activity of Extracts from Some Edible Plants Commonly Consumed in Asia. Int. J. Food Microbiol. 2003, 80, 223-230. [CrossRef]

25. Nayan, R.B.; Shukla, V.J. Antibacterial and Antifungal Activities from Leaf Extracts of Cassia fistula L.: An Ethnomedicinal Plant. J. Adv. Pharm. Technol. Res. 2001, 2, 104-109.

26. ISO 1522 Paints and Varnishes-Pendulum Damping Test; ISO: Geneva, Switzerland, 2007.

27. JIS K 5400 Testing Methods for Paints; Japanese Standards Association: Tokyo, Japan, 1990.

28. CNS 10756 K6800 Method of Test for Paints (Film Formability of Paints); CNS: Taipei, Taiwan, 1994.

29. Kelton, K.F.; Greer, A.L. Heterogeneous Nucleation in Pergamon Materials Series; Elsevier Ltd.: Amsterdam, The Netherlands, 2010; Volume 15, Chapter 6; ISSN ISSN 1470-1804. [CrossRef]

30. Díaz-Visurraga, J.; Gutiérrez, C.; Plessing, C.V.; García, A. Metal N-nanostructures as Antibacterial Agents. Science Against Microbial Pathogens: Communicating Current Research and Technological Advances; Formatex Research Center: Badajoz, Spain, 2011; pp. 210-218.

31. Chang, C.W.; Lee, H.L.; Lu, K.T. Manufacture and Characteristics of Oil-Modified Refined Lacquer for Wood Coatings. Coatings 2019, 9, 11. [CrossRef]

32. Arrighi, V.; McEwen, I.J.; Qian, H.; Serrano Prieto, M.B. The Glass Transition and Interfacial Layer in Styrene-butadiene Rubber Containing Silica Nanofiller. Polymer 2003, 44, 6259-6266. [CrossRef]

33. Javni, I.; Petrović, Z.S.; Guo, A.; Fuller, R. Thermal Stability of Polyurethanes Based on Vegetable Oils. J. Appl. Polym. Sci. 2000, 77, 1723-1734. [CrossRef]

34. Ling, J.S.; Mohammed, I.A.; Ghazali, A.; Khairuddean, M. Novel Poly(alkyd-urethane)s from Vegetable Oils: Synthesis and Properties. Ind. Crops Products 2014, 52, 74-84. [CrossRef]

35. Hablot, E.; Zheng, D.; Bouquey, M.; Ave'rous, L. Polyurethanes Based on Castor Oil: Kinetics, Chemical, Mechanical and Thermal Properties. Macromol. Mater. Eng. 2008, 293, 922-929. [CrossRef]

36. Chang, C.W.; Lu, K.T. Linseed-oil-based Waterborne UV/air Dual-cured Wood Coatings. Prog. Org. Coat. 2013, 76, 1024-1031. [CrossRef]

37. Chang, C.C.; Chang, C.H. Preparation and Characterization of Polyurethane-gold Nanocomposites Prepared Using Encapsulated Gold Nanoparticles. Polym. Int. 2010, 59, 910-916. [CrossRef] 